\title{
"A Clinicoradiological and Craniofacial Biomechanical Evaluation of Temporomandibular Joint Disorders in Designing a New Diagnostic Module."
}

\author{
Dr.Samir D. Khaire ${ }^{1}$, Dr. Chandrakant P. Taware ${ }^{2}$, \\ ${ }^{1}$ Assistant Professor, Maxillofacial and Oral Surgeon, Department Of Dentistry, Byramjee Jeejeebhoy \\ Government Medical College \& Sassoon General Hospitals’ Pune. \\ ${ }^{2}$ Ex- Joint Director (DMER, Mumbai), Ex-Professor \& Head of the Department of Oral and Maxillofacial \\ Surgery, Government Dental College \& Hospital, Mumbai
}

\begin{abstract}
The temporomandibular joint is an important joint in the human body. It is a joint, just like any other joint in the body, yet it is different in that there are two joints connected by a single bone-the mandible. Normal development of the temporomandibular joint is important which not only helps in the development of normal facial contours of the lower third of the face, but also plays an important role in enabling the person to perform primary functions of life such as feeding, sucking, and speech. Synchronous movement of both the joints is important for carrying out the functions smoothly. The disorders affecting the temporomandibular joints can be of the acquired or the congenital type. Both types can cause degeneration of the joint tissues and leave the patient handicapped for many functions.

The concepts of biomechanics and functional matrix theory have been made use of in this project and an attempt has been made to understand the causes of the various clinical presentations. The project attempts to develop a diagnostic tool which will correlate the clinical presentation of the patients and the radiological findings along with an understanding of the biomechanics of the TMJ.
\end{abstract}

\section{Introduction}

Temporomandibular joint disorders are a group of disorders whose aetiopathogenesis has been incompletely understood. The disorder may be either primary in nature or it may be one of the manifestations of an underlying systemic disease. In addition, the clinical presentations are so varied that it is difficult to define the exact nature of the disorder. To add to this problem is the complexity of the temporomandibular joint apparatus and it's relations at the level of the base of the skull.

Diagnostic modalities have undergone a revolution with the CT scan and MRI replacing the age-old investigative procedures. However, with the advances in imaging techniques, the costs of these procedures have also increased and they are not affordable to the common person. The diagnostic modalities available rely either only on the clinical presentation of the patient or on the radiological findings. However, the available diagnostic modalities have shown little promise in defining the exact nature of the disease. As the exact nature of the disease has not yet been clearly defined the treatment rendered to the patient is symptomatic. However, the root cause for the disorder is never eliminated owing to the shortcomings of the present diagnostic modalities. Only when a correct diagnosis is made can the treatment plan give complete cure to the patient. Thus, there is still scope for improvement in the field of diagnosis of the nature of the TMJ disorders.

Biomechanics of joint activities is influenced largely by the development of the articulating bones forming the joint. It is the science that investigates and analyzes human motion. Biomechanics in relation to the maxillofacial skeleton focuses on motions and functions of the jaw and oral musculature. A correlation between the clinical presentation of the patients with TMJ disorders, their radiological findings and an understanding of the functional biomechanics of the joint is mandatory in deciding the appropriate treatment plan.

The limitations and drawbacks of the various diagnostic aids and the seriousness of the nature of the disorders and alarming rise in cases in recent years warrants a firm approach to the management of the pathological condition and a quest to explore the new horizons in the field of diagnosis.

\section{Aims And Objectives}

The study was undertaken with the following aims and objectives in mind:

1) To evolve a module for submentovertex cephalometrics.

2) To correlate submentovertex cephalometrics with lateral cephalometrics.

3) To understand the biomechanical principles of temporomandibular joint. 
4) To understand and define articular relationship of condylar head with the base of the skull either in motion or at rest position and evolve the concept of biomehanics and correlate it with the biomechanical principles of the TMJ.

5) To study the interrelationship of mandible and maxilla to the base of the skull.

6) To correlate social-psychological, clinical and radiological parameters in patients with temporomandibular joint disorders with reference to TMJ biomechanics.

7) To develop an improved version of diagnostic tool and thereby to be used for deciding the precise treatment protocol.

\section{Materials And Methods}

In this study, an attempt has been made to understand the role played by the form of the articulating surfaces of the TM Joint on it's functioning. Five healthy individuals from Government Dental College and Hospital, Mumbai, who had no TM joint problems, were selected and labelled as control group. A thorough clinical examination was carried out followed by radiographic examination, which included an orthopantomogram, lateral cephalogram and a digital submentovertex X-ray. Certain linear and angular measurements done on these X-rays helped in understanding the biomechanics of the joint at the level of the base of the skull. The psychological status of these control group individuals was also recorded. These readings of the clinical, radiological, biomechanical and psychological parameters for the control group were recorded and used as a baseline for comparison for the patients with TM joint disorders. Twenty-two patients with signs and symptoms of TM joint disorders were then selected from the outpatient department of the same institution and were labelled as test group. The clinical, radiological, biomechanical and psychological parameters for the test group were noted. The variations in the values recorded for the test group patients from the control group values was used to explain the various clinical presentations exhibited by the TMJ disorder patients. The ethical committee approval was taken for the study.

Patient selection criteria for the control group:

1) Healthy individuals, in the age range of 20-30 years (2 males and 3 females); from urban population, from Government Dental College and Hospital, Mumbai, whose mental and physical development was satisfactory, were selected. Particular attention was given to see that the head-neck-face region had grown up ideally with normal dentition, having Angle's class I molar relationship.

2) Control group individuals had bilaterally symmetrical facial appearance.

3) The individuals had no signs of TMJ disorders on clinical examination. (eg. pain, clicking, deviation of the jaw, trismus, myofascial pain dysfunction syndrome).

\section{Patient selection criteria for the test group:}

1) Patients, irrespective of their age, sex, occupation, were selected from the rural as well as urban population.

2) The patients, with and without systemic problems, were included in the test group.

3) Patients with signs and symptoms of congenital or acquired TM joint disorders were included. (eg. Pain in the preauricular region, tenderness on palpation of the masticatory muscles, clicking of temporomandibular joint, deviation of the jaw on opening, trismus (excluding space infection).

4) Special attention was paid in selecting patients having structural deformities or MPDS because of TM joint problems.

After the patients for control group and test group were selected, a thorough case history of the patient was taken along with clinical examination with particular emphasis on examination of the head-neck-face region. The data thus gathered during the examination was recorded in the case history proforma.

\section{Patient Assessment Observation Criteria}

1) Clinical examination.

Defined criteria for the clinical data findings

(1) Occlusion: Occlusion will be observed and noted on the basis of Angle's classification and its related subdivisions and modifications and any deviations from the normal designated by various terminologies as follows:

- OCR-I: (Occlusion in centric relation-classI) designates class I relationship of the jaws with normal dental relations in anteroposterior, mediolateral and superoinferior planes.

- OCR-II: (Occlusion in centric relation-classII) designates class II relationship of the jaws and the dentition.

- OCR-III: (Occlusion in centric relation-classIII) designates class III relationship of the jaws and the dentition. 
- Along with the type of occlusion, other relevant findings were recorded in abbreviation forms as follows:

- $\mathrm{C}-\mathrm{G} ; \mathrm{P}$ ( $\mathrm{a}, \mathrm{b}, \mathrm{c}, \mathrm{d})$ : $\mathrm{C}=$ Crowding of teeth. $\mathrm{G}=$ generalized; $\mathrm{P}=$ particular region. $\mathrm{a}=$ maxillary right quadrant; $b=$ maxillary left quadrant; $c=$ mandibular left quadrant; $d=$ mandibular right quadrant.

- $\quad$ S-G; $P$ (a, b, c, d): S = Spacing of teeth. $G$ = generalized. $P$ = particular region. a = maxillary right quadrant; $\mathrm{b}=$ maxillary left quadrant; $\mathrm{c}=$ mandibular left quadrant; $\mathrm{d}=$ mandibular right quadrant.

- Pn, Rn-Mxt / Mt: Pn = Proclination of teeth. $\mathrm{Rn}=$ retroclined teeth. $\mathrm{Mxt}=$ maxillary teeth and $\mathrm{Mt}=$ mandibular teeth.

- $\operatorname{Pr}, \mathrm{Rr}-\mathrm{Mx} / \mathrm{Mn}: \mathrm{Pr}=$ protrusion; $\mathrm{Rr}=$ retrusion; $\mathrm{Mx}=$ maxilla; $\mathrm{Mn}=$ mandible.

- AD: Anterior deep bite.

- AC: Anterior cross bite.

- $\quad$ PC-u, b: Posterior cross bite. $\mathrm{u}=$ unilateral; $\mathrm{b}=$ bilateral.

- $\quad$ PO-u, b: Posterior open bite. $\mathrm{u}=$ unilateral; $\mathrm{b}=$ bilateral.

- AO: Anterior open bite.

- BMP: Bimaxillary protrusion.

- $\quad$ OCR-Cn (L) or (R): Occlusion in centric relation with canting either to left (L) or to right (R).

- Miscellaneous:

FR-u, b-L, R: Faulty restoration.

Mi-u, b-L, R: Malposed tooth.

I-u, b-L, R: Impacted teeth.

$\mathrm{u}=$ unilateral; $\mathrm{b}=$ bilateral; $\mathrm{L}=$ left; $\mathrm{R}=$ right.

(2) Mandibular Excursive Movements

- $\quad$ NEM : Normal mandibular excursive movements.

- $\quad$ CLC-u -L/R; b: CLC = clicking of the condyles during excursive movements. $\mathrm{u}=$ Unilateral; $\mathrm{L}=\mathrm{left}, \mathrm{R}=$ right. $\mathrm{b}=$ bilateral.

- $\mathrm{DM}-\mathrm{u}-\mathrm{L} / \mathrm{R}-\mathrm{b}-\mathrm{g} / \mathrm{h}-: \mathrm{DM}=$ deviation of the mandible during excursive movements. $\mathrm{u}=\mathrm{Unilateral} ; \mathrm{L}=$ left; $\mathrm{R}=$ right. $\mathrm{b}=$ bilateral

- $\quad \mathrm{g} / \mathrm{h}=$ deviation of the mandible during excursive movements with pain or without pain respectively.

- SL; DL with CLC and with P; SL; DL without CLC and without P: SL = Subluxation. DL = dislocation. $\mathrm{CLC}=$ clicking of TMJ. $\mathrm{P}=$ pain.

(3) Muscle Status in Head- Neck Region

\section{Extraoral}

NM : No abnormality detected in the muscles of the head-neck region.

Dy; Hy; Ag -i, j, k, l: Dy = Dystrophy. Hy = hypertrophy. Ag = agenesis. $\mathrm{i}=$ facial muscles; $\mathrm{j}=$ muscles of the neck; $\mathrm{k}=$ suprahyoid muscles; $\mathrm{l}=$ Infrahyoid muscles.

\section{Intraoral}

NM: No abnormality detected in the muscles of the oral region.

Tg-Mag; Mig; Ag: Tg = Tongue. Mag = Macroglossia, Mig = Microglossia, Ag = ankyloglossia.

ASP: Abnormality detected in the musculature of the soft palate.

AOP: Abnormality detected in oropharyngeal musculature.

Miscellaneous

Fl: Flaccid; Ht: Hypertonic; Mt: Muscle twitching; Sc: Scarring; Ct: Contracture.

(4) Maxillofacial Skeletal Structure

NSS: Normal skeletal structure.

Asy -U3/M3/L3-mi/mo/se: Asy = Asymmetry. U3 = upper 1/3rd of the maxillofacial skeleton; M3 = in middle $1 / 3 \mathrm{rd}$ of the maxillofacial skeleton; L3 = lower 1/3rd of the maxillofacial skeleton which was graded as mild (mi), moderate (mo) or severe (se).

$\square \quad$ Ag; Hp; Hr- U3/M3/L3 - u - L or R / b : Ag = Agenesis; Hp = hypoplasia; Hr = hyperplasia. U3/M3/L3 = some component of the maxillofacial skeletal structure either in the upper $1 / 3 \mathrm{rd}$ or in middle $1 / 3 \mathrm{rd}$ or in lower $1 / 3$ rd of the maxillofacial skeleton. $\mathrm{u}=$ unilateral; $\mathrm{b}=$ bilateral; $\mathrm{L}=$ left; $\mathrm{R}=$ right.

(5) Clinical Presentation

\section{Score for pain:}

- Score 0: No pain (subjective) which was confirmed clinically with thorough examination eliminating possible causative factors for any type of pain reaction. 
- Score 1: Mild pain obviously exhibited subjectively within the tolerable limits and clinically confirmed with obvious signs and symptoms of inflammation and swelling with no restriction of day-to-day activities as well as maxillofacial movements.

- Score 2: Moderate pain observed at the verge of maximum tolerance limits subjectively resulting in restriction of day-to-day activities and painful maxillofacial movements and may be associated with moderate inflammation and swelling.

- Score 3: Severe pain. Unbearable pain exhibited with screaming and change of posture, which is confirmed clinically and may be associated with severe inflammation and swelling.

\section{Score for inflammation:}

- Score 0: No inflammation on clinical examination and no signs of pain or swelling.

- Score 1: Mild inflammation as observed clinically and associated with mild pain and swelling.

- Score 2: Moderate inflammation as observed clinically and associated with moderate pain and swelling.

- Score 3: Severe inflammation as observed clinically and associated with severe pain and swelling

Score for swelling of the soft tissues: (Di: Diffuse. De: Demarcated)

- Score 0: No swelling in soft tissues.

- Score 1: Mild swelling in the soft tissues with a diameter of approximately $2.0-5.0 \mathrm{~mm}$ and may be associated with mild pain and inflammation.

- Score 2: Moderate swelling in the soft tissues with a diameter of approximately $5.0-10.0 \mathrm{~mm}$ and may be associated with moderate pain and inflammation.

- Score 3: Severe swelling in the soft tissues with a diameter exceeding $10.0 \mathrm{~mm}$ and may be associated with severe pain and inflammation.

2) Radiological examination and biomechanical evaluation.

The radiological examination consisted of taking three X-rays for the patient, namely an orthopantomogram (OPG), a lateral cephalogram and a submentovertex X-ray (SMV). The OPG and lateral cephalogram were taken at the Department of Oral Diagnosis, Medicine and Radiology, GDCH, Mumbai. The SMV was done at Jhankaria Imaging, Prarthana Samaj, Mumbai.

The outline of the mandible along with the dentition and the skeletal structures of the zygomaticomaxillary complex on both the sides were traced for the orthopantomogram. The mandibular foramen was located relative to measurements done on the $\mathrm{X}$-and $\mathrm{Y}$-axis as drawn on a graph paper and held in relation to the tracing paper. The magnification factor in an OPG was taken into consideration. However, the measurements were done to define a plane passing through the lingulae and not to exactly demarcate the position of the lingulae. These measurements were then used for locating the lingula when taking the submentovertex projection. Once the tracing of the outline of the soft tissues and bony structures was completed on the lateral cephalogram, then the following landmarks were identified on the tracing.First, the porion and ortibale were identified to establish the Frankfort horizontal plane.

- Orbitale: To locate orbitale, one end of a ruler was placed tangent to the top edge of the external auditory meatus and the other end was moved upward until it first touched the infraorbital rim of the orbit; this point was orbitale.

- Porion: Now, using orbitale as a reference point and holding the straight edge in place, the outermost and most superior point of the external auditory meatus was designated as porion.

- After the orbitale and porion were located, they were joined to establish the Frankfort horizontal (F-H) plane.

- $\quad \mathbf{N}$ : nasion. The most anterior point on the frontonasal suture in the midsagittal plane.

- S: Sella: Geometric center of the pituitary fossa located by visual inspection.

- After the sella and nasion were located they were joined to establish the sella-nasion (S-N) plane.

- ANS: Anterior nasal spine: Anterior tip of the nasal spine.

- PNS: Posterior nasal spine: Using a line perpendicular to FH, PNS was located at the most posterior aspect of the palatine bone.

- Point A: Again, using a line perpendicular to FH plane, the most posterior point in the concavity between ANS and the maxillary alveolar process was located.

- Point B: On a line perpendicular to FH, point B was the most posterior point in the concavity between the chin and mandibular alveolar process.

- Occlusal Plane: The occlusal plane was drawn through the region of the overlapping cusps of the first premolars and first molars. 
- Go: Gonion: Two lines were drawn, one tangent to the inferior border of the mandible and the other tangent to the posterior border of the ramus. The gonion was located on the curvature of the mandibular angle by bisecting the angle formed by the two lines.

- Pg: Pogonion: The perpendicular line to FH plane was moved forward then back to where it first touched the chin; this was pogonion.

- Me: Menton: With a scale held parallel to FH plane, move the straight edge was moved upward until it first touched the inferior border of the symphysis of the mandible; this point was menton.

- Gn: Gnathion: The gnathion was located midway between pogonion and menton on the outline of the symphysis.

- Mandibular Plane: The mandibular plane was drawn between gonion (Go) and gnathion (Gn).

- Once the landmarks and planes were identified, the following angles were measured on the tracing and recorded in the observation tables.

- Angle SNA

- Angle SNB

- Angle ANB

- Angle formed between the occlusal plane and the S-N plane.

- $\quad$ Angle formed between the mandibular plane and the S-N plane.

The digital submentovertex X-rays (SMV) were taken with the patient laid supine on the table. Prior to placing the cassette, the measurements done on the OPG were transferred to the skin of the patient with the help of $5 \mathrm{~mm} \times 5 \mathrm{~mm}$ thin lead film piece.

The SMV X-ray was interpreted to assess the symmetry of the skull base as well as the mandible and the zygomaticomaxillary complex. The shape of the condyle was classified into three types, namely, an oblong shape (type A), a rounded to oval shape (type B) and a pear shaped (type C). Assessment of the anterior, middle and posterior cranial fossae were done on the SMV to note if any abnormality could be detected.

The SMV X-ray was also traced and the following landmarks and planes were defined ${ }^{1}$.

- Foramina spinosa points (FSP): -The geometric center of each foramen spinosa (FS). The interspinosum line connects the right and left foramen spinosa points.

- Midsagittal plane: A perpendicular bisector of the line joining the two foramen spinosum was defined as the midsagittal plane.

- Gonion point (Go): -The midpoint mediolaterally on the posterior border of each gonial angle (G).

- Mandibular body lines are reference lines which were constructed as follows. The midpoint mediolaterally of the mandibular body at the distal aspect of each mandibular first molar was determined. A line was drawn from this point through gonion point, extending posteriorly through the condyle on each side.

- Condylion anterioris. (CA): -The intersection of the mandibular body line with the anterior border of each condyle (C).

- $\quad$ ondylion posterioris (CP): -The intersection of the mandibular body line with the posterior border of each condyle.

- Condylion lateralis (CL): -The tangent point to each lateral condylar border of a line drawn parallel to each mandibular body line.

- Condylion medialis (CM): - The tangent point to each medial condylar border of a line drawn parallel to each mandibular body line.

Once the CL and CM points were identified, they were joined to define the horizontal condylar axis. This axis was traced medially until it intersected the midsagittal plane. The condylar angles were measured in relation to the midsagittal plane. In addition, the intercondylar axis angle was measured at the meeting point of the two condylar axes. The approximate position of the lingulae were identified by the radiopaque shadow cast on the submentovertex x-ray by the $1 \mathrm{~mm}$ x $1 \mathrm{~mm}$ lead film placed externally over the skin of the patient. The midpoint of the radiopaque shadow was identified and the two points were joined by a line to define the axis passing through the lingulae (the transverse mandibular axis). This axis intersected the midsagittal plane at a particular point thereby forming an angle with it. This angle was measured. The transverse mandibular axis also intersects the individual condylar axes thereby forming angles with them which were also measured.

After the tracings of the respective X-rays were completed and the linear and angular measurements were done, the data was then fed in observation tables using the followings keys.Defined criteria for radiological and biomechanical data findings Orthopantomogram findings

1) Bon.qua. = bone quality. 
$\mathrm{G}=\operatorname{good}$ bone quality. Bone with cortical border, which is smooth, without interruption and has symmetrical thickness in comparable anatomic areas (eg. Angle of mandible, inferior border of mandible, posterior border of rami) and with normal trabecular pattern. $\mathrm{M}=$ moderate bone quality. Bone with thinned cortical outline which is asymmetrical and with altered trabecular pattern.

$\mathrm{P}=$ poor bone quality. Bone with cortical outline, which is interrupted in certain areas, and with highly altered trabecular pattern with presence of pathological conditions as identified on radiographs.

\section{2) Dentition.}

Pr; Mi; Per; E -No, Ab-an, po-L, R. Pr = primary dentition; Mi = mixed dentition; Per = permanent dentition; E $=$ edentulous; $\mathrm{No}=$ normal; $\mathrm{Ab}=$ abnormal; $\mathrm{an}=$ anterior; $\mathrm{po}=$ posterior; $\mathrm{L}=$ left $\mathrm{R}=$ right.

Perio.dis: Periodontal disease. Abs = absent; Gen = generalized; Loc $=$ localised .

\section{3) Mandible.}

Cond.: Condyle.

$\mathrm{NCM} ; \mathrm{FC} ; \mathrm{SC} ; \mathrm{EAS}-\mathrm{u}, \mathrm{b} . \mathrm{NCM}=$ normal condylar morphology; $\mathrm{FC}=$ flattening of the condyle; $\mathrm{SC}=$ subchondral sclerosis; EAS = erosions of the articulating surfaces; $u=$ unilateral; $b=$ bilateral

Coro-No, Ab-L, R. Coro. = coronoid process. No = normal; $\mathrm{Ab}=$ abnormality seen in the coronoid processes; $\mathrm{L}$ $=$ left; $\mathrm{R}=$ right.

Symm = symmetry between the two halves of mandible. Sy = symmetrical; Asy; mi, mo, se. Asy = asymmetrical mi $=$ mild $;$ mo $=$ moderate; $\mathrm{se}=$ severe.

4) Midfacial region

Max $=$ maxilla. Sy $=$ symmetry seen in the outline of the two maxillae. Asy $=$ asymmetry seen in the outline of the two maxillae.

Max.sin. = maxillary sinus. CO-c, in. $\mathrm{CO}=$ cortical outline; $\mathrm{c}=$ continuous; in = interrupted; RD-com, rsd, lsd. $\mathrm{RD}=$ Radiographic density. com = comparable; rsd = right maxillary sinus is more radiodense than left; lsd $=$ left maxillary sinus is more radiodense than right.

Zyg.com. = Zygomaticomaxillary complex. Sy = symmetrical; Asy = asymmetrical .

5) Misc $=$ miscellaneous. Non-specified findings such as infections, pathological lesions.

$\mathrm{I}$-u, b. I = Impacted teeth; $\mathrm{u}=$ unilateral; $\mathrm{b}=$ bilateral.

$\mathrm{Re}-\mathrm{u}, \mathrm{b} . \mathrm{Re}=$ restored teeth; $\mathrm{u}=$ unilateral; $\mathrm{b}=$ bilateral

Mi-u, b -an, po-L, R. M = missing teeth; $\mathrm{u}=$ unilateral; $\mathrm{b}=$ bilateral; $\mathrm{an}=$ anterior, po = posterior, $\mathrm{L}=$ left, $\mathrm{R}=$ right.

St-e-u, b. $\mathrm{St}=$ styloid process; $\mathrm{e}=$ elongated $; \mathrm{u}=$ unilateral $; \mathrm{b}=$ bilateral.

$\mathrm{F}-\mathrm{u}, \mathrm{b}$-an, po-L, R. F = fractured tooth, $\mathrm{u}=$ unilateral; $\mathrm{b}=$ bilateral; $\mathrm{an}=$ anterior; po = posterior; $\mathrm{L}=$ left; $\mathrm{R}=$ right

\section{Lateral cephalogram data findings}

1) $\mathrm{CB}-\mathrm{Mx}=$ Relationship of maxilla to cranial base.

No = normal; wherein the maxilla is positioned normally in relation to the cranial base as evidenced by the angle SNA $\left(82^{0}+/-2^{0}\right)$

Pro-max-mi; mo; se. Pro $=$ Prognathic $\max =$ maxilla. Maxilla is positioned anteriorly in relation to the cranial base as evidenced by the angle SNA. (SNA is more than $84^{\circ}$.)

Pro-max $-\mathrm{mi}=$ mild which is indicated by angle SNA which ranges from $84^{0}-86^{\circ}$; Pro-max-mo $=$ moderate which is indicated by angle SNA which ranges from $87^{0}-90 .^{\circ}$ Pro-max- se $=$ severe which is indicated by angle SNA which ranges from $91^{0}$ and above.

Retro-max-mi, mo, se. Retro = retrognathic. Maxilla is positioned posteriorly in relation to the cranial base as evidenced by the angle SNA. (SNA is less than $80^{\circ}$.)

Retro-max-mi $=$ mild retrognathism as indicated by SNA angle, which ranges from $76^{0}-79 .{ }^{0}$; Retro-max-mo = moderate retrognathism as indicated by SNA angle, which ranges from $72^{0}-75 .^{0}$ Retro-max-se: severe retrognathism as indicated by SNA angle, which ranges from $71^{\circ}$ and below.

2) $\mathrm{CB}-\mathrm{Mn}=$ Relationship of mandible to the cranial base.

No = normal; wherein the mandible is positioned normally in relation to the cranial base as evidenced by the angle SNB $\left(80^{0}+/-2^{0}\right)$.

Pro-man-mi; mo; se. Pro = Prognathic. Man = Mandible. Mandible is positioned anteriorly in relation to the cranial base as evidenced by the angle SNB. (SNB is more than $82^{\circ}$.)

Pro-man-mi = mild prognathic mandible as evidenced by angle SNB that ranges from $83^{0}-86 .{ }^{0}$ Pro-man-mo = moderate prognathic mandible, which is evidenced by angle SNB which ranges from $87^{0}-91 .^{0}$ Pro-manse: severe prognathic mandible evidenced by SNB angle, which is above $91 .^{0}$ 
Retro-man- mi; mo; se. Retro = retrognathic. Mandible is positioned posteriorly in relation to the cranial base as evidenced by the angle SNB.(SNB is less than $78^{0}$.)

Retro-man-mi = mild retrognathism as indicated by SNB angle, which ranges from $74^{0}-77 .{ }^{0}$; Retro-man-mo = moderate retrognathism as indicated by SNB angle, which ranges from $70^{\circ}-73 .{ }^{\circ}$ Retro-man-se: severe retrognathism as indicated by SNB angle, which is below $70^{\circ}$.

3) $\mathrm{Mx}-\mathrm{Mn}=$ Relationship of maxilla to mandible.

No = normal; wherein the maxilla and mandible are positioned in a normal relation as judged by the angle $\mathrm{ANB} .\left(\mathrm{ANB}=2^{0}\right)$.

$\mathrm{Ab}=$ abnormal; wherein angle ANB is either less than $1^{0}$ or more than $3^{0}$.

4) MIP = maxillary incisor position.

No $=$ normal; wherein the distance from the most anteriorly placed point on upper central incisor to the $\mathrm{N}-\mathrm{A}$ line is $4 \mathrm{~mm}+/-1 \mathrm{~mm}$ and the axial inclination of the central incisor to the N-A line is $22^{0}+/-2$. $^{0}$

Prot = protruded; wherein the distance from the most anteriorly placed point on upper central incisor to the N-A line is more than $5 \mathrm{~mm}$ and the axial inclination of the central incisor to the N-A line is more than 24 . $^{\circ}$

Ret = retruded; wherein the distance from the most anteriorly placed point on upper central incisor to the N-A line is less than $3 \mathrm{~mm}$ and the axial inclination of the central incisor to the N-A line is less than $20 .^{\circ}$

5) MaIP = mandibular incisor position.

No = normal; wherein the most labial portion of the crown of the lower incisor is $4 \mathrm{~mm}+/-1 \mathrm{~mm}$ ahead of the N-B line and the axial inclination of the tooth to the N-B line is $25^{\circ}+/-2^{0}$

Prot = protruded; ; wherein the distance from the most anteriorly placed point on lower central incisor to the N-B line is more than $5 \mathrm{~mm}$ and the axial inclination of the central incisor to the N-B line is more than $27 .{ }^{0}$

Ret = retruded; wherein the distance from the most anteriorly placed point on lower central incisor to the N-B line is less than $3 \mathrm{~mm}$ and the axial inclination of the central incisor to the N-B line is less than $23 .^{\circ}$

6) Misc = Miscellaneous. Any other significant finding not included in the key is added here.

Submentovertex data findings

1) Symm = symmetry. Sy; Asy-mi, mo, se. Sy = symmetric outline of skull base. Asy = asymmetry observed in the outline of skull base. $\mathrm{Mi}=$ mild; $\mathrm{mo}=$ moderate; se = severe.

2) Mand = mandible.

Symm= symmetry between the two halves of mandible. Sy = symmetrical; Asy; mi, mo, se. Asy = asymmetrical. $\mathrm{mi}=$ mild; $\mathrm{mo}=$ moderate; $\mathrm{se}=$ severe. laterally.

Cond.sh = condyle shape. $\mathrm{A}=$ oblong; $\mathrm{B}=$ rounded to oval: $\mathrm{C}=$ pear shaped i.e. tapering medially or

3) Zyg.com. = Zygomaticomaxillary complex. Sy = symmetric; Asy= asymmetric. (Which may include depressed arches, malunited fractures of the complex)

4) $\mathrm{Ba.Sk}$. = base of the skull. No = normal; Ab-acf, mcf, pcf = abnormal (which may include pathologies of the anterior cranial fossa, middle cranial fossa or posterior cranial fossa.)

5) Misc $=$ miscellaneous. Any other finding which is not specified in the above mentioned categories.

$\mathrm{Re}-\mathrm{u}, \mathrm{b}-\mathrm{L}, \mathrm{R} . \mathrm{Re}=$ restorations; $\mathrm{u}=$ unilateral; $\mathrm{b}=$ bilateral; $\mathrm{L}=$ left; $\mathrm{R}=$ right.

Cranial base reference system

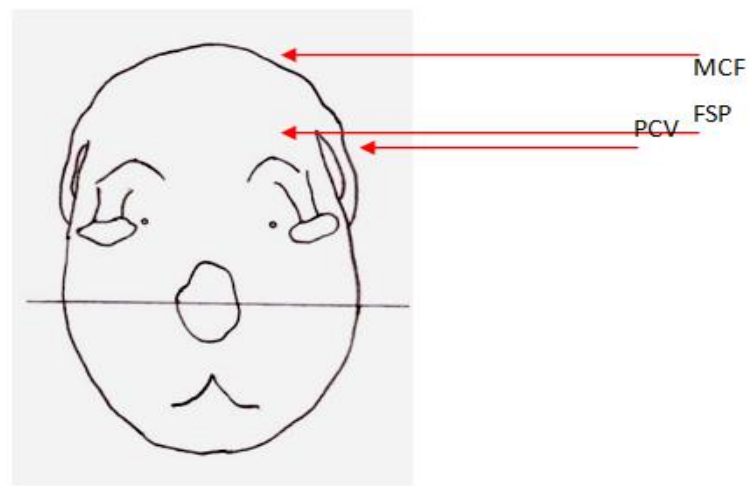

Schematic diagram showing the points marked in the cranial base reference system.MCF

Middle cranial fossa: FSP: Foramina spinosa point; PCV: Posterior cranial vault 
The landmarks chosen for the analysis of cranial base symmetry are the right and left foramina spinosa, right and left lateral borders of the cranial vault, right and left middle cranial fossa.

Foramina spinosa points (FSP): The geometric center of each foramen spinosa (FS). The interspinosum line connects the right and left foramen spinosa points. The interspinosum axis is the perpendicular bisector of the interspinosum line. Measurements to assess bilateral symmetry within the cranial base were made relative to a coordinate axis system consisting of the interspinosum line, which serves as the X-axis, and the interspinosum axis, which serves as the $\mathrm{Y}$-axis. The intersection of the interspinosum line-and axis is the zero point or origin of the axis system. Each data point was assigned a pair of Cartesian coordinates ( $\mathrm{x}, \mathrm{y}$ ), based upon its distance in millimeters, in the horizontal and transverse dimensions from the origin.

PCV: Posterior cranial vault point. The intersections of the lateral borders of the cranial vault with a line, parallel to the interspinosum line, which is drawn across the cranial vault at its section of greatest width. L $=$ left point. $\mathrm{R}=$ right point. $\mathrm{MCF}$ : Middle cranial fossa point.

\section{Maxillary reference system}

The analysis of the zygomaxillary complex requires the tracing of the zygomaxillary arches, pterygomaxillary fissures. Pterygomaxillary fissure (PTM): The most medial and posterior point of each pterygomaxillary fissure. The PTM line connects the right and left PTM points. The PTM axis is the perpendicular bisector of the PTM line. Measurements to assess bilateral symmetry within the zygomaxillary complex were made relative to a co-ordinate axis system consisting of the PTM line, which serves as the X-axis and the PTM axis, which serves as the Y-axis. The intersection of the PTM line and axis is the origin or zero point from which all measurements were made.

ZP: Zygion point. The intersections of the lateral borders of the zygomatic arches with a line, parallel to the PTM line, which is drawn across the section of greatest bizygomatic width.

MCV: Middle cranial vault point. The points where the lateral borders of the cranium are intersected by a line connecting the right and left zygion points.

Ang: Angulare point. The most anterior points relative to the PTM line, of the triangular opacities present at the external orbital angle where the upper and lower orbital rims meet and the zygomatic arch inserts.

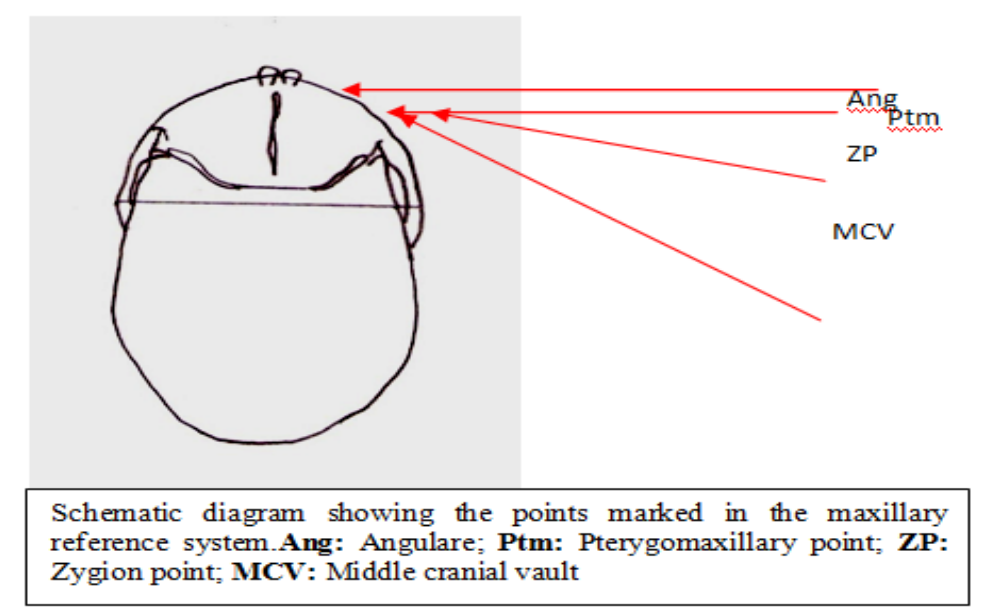

\section{Mandibular reference system}

Condylion line connects the right and left condylion anterioris points. Condylion axis is the perpendicular bisector of the condylion line. Measurements to assess bilateral symmetry within the mandible were made relative to a coordinate axis system consisting of the condylion line, which serves as the $\mathrm{X}$-axis, and the condylion axis, which serves as the Y-axis. The intersection of the condylion line and axis is the zero point, or origin from which all measurements are made. Each data point is assigned a pair of Cartesian coordinates. 


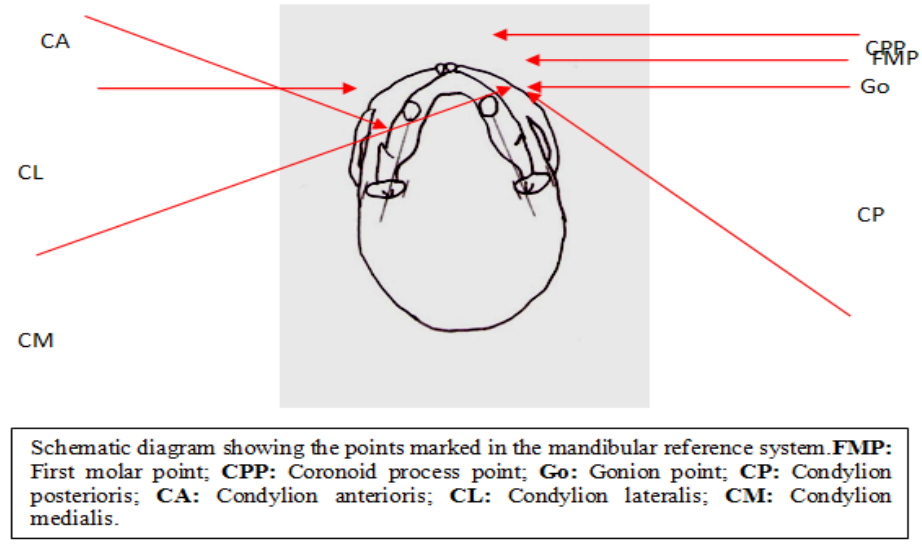

CA: Condylion anterioris. The intersection of the mandibular body line with the anterior border of each condyle. Mandibular body lines are reference lines which are constructed as follows. The midpoint mediolaterally of the mandibular body at the distal aspect of each mandibular first molar is determined. A line is drawn from this point through gonion point, extending posteriorly through the condyle on each side.

Go: Gonion point. The most posterior and medial point of the angle of the mandible is called the gonion.

CP: Condylion posterioris. The intersection of the mandibular body line with the posterior border of each condyle.

CM: Condylion medialis. The tangent point to each medial condylar border of a line drawn parallel to each mandibular body line.

CL: Condylion lateralis. The tangent point to each lateral condylar border of a line drawn parallel to each mandibular body line.

CPP: Condylion process point. The most anterior point, relative to the condylion line, on each coronoid process.

RCAa: Right condylar axis angle formed between the right condylar axis (RCA) and midsagittal plane (MSP). Right condylar axis is defined as the line passing through CM and CL of the right condyle. Midsagittal plane is defined as the line which divides the skull outline in two equal halves and passing through the nasopalatine foramen, posterior nasal spine, and foramen magnum.

LCAa: Left condylar axis angle formed between the left condylar axis (LCA) and MSP. Left condylar axis is defined as the line passing through CM and CL of the left condyle.

ICAa: Intercondylar axis angle formed by the intersection of the RCA and LCA.

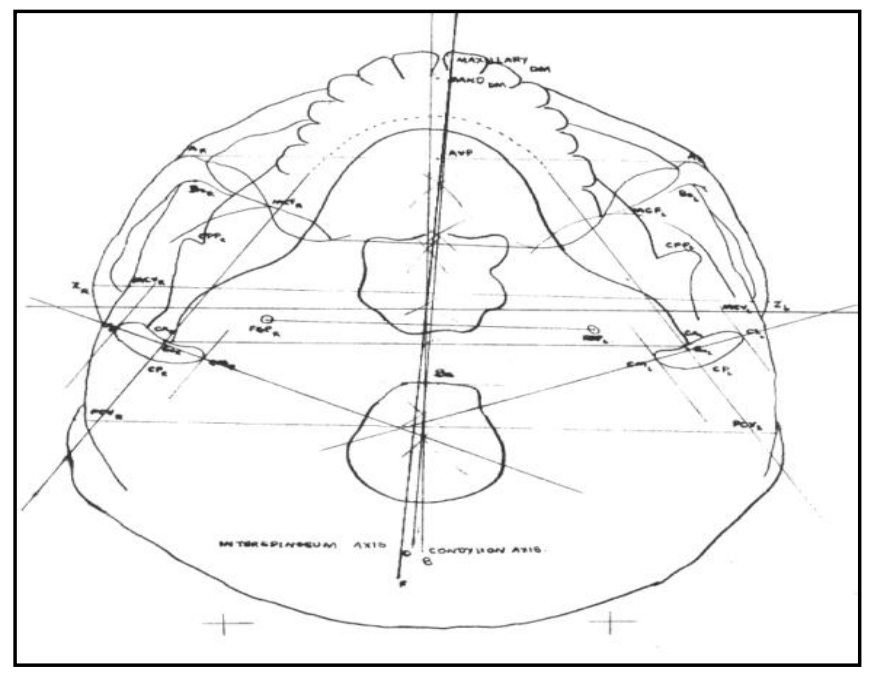

LANDMARKS IDENTIFIED IN THE TRACING

FSP: Foramen spinosum. The line joining the two FSP points is the interspinosum line. The perpendicular bisector of the interspinosum line is the interspinosum axis (also defined as the midsagittal plane for our studt).

MCF: Middle cranial fossa point. PCV: Posterior cranial vault point.

PTM: Pterygomaxillary point. The line joining the two PTM points is the PTM line. The perpendicular bisector of the PTM line is the PTM axis.

Ang: Angulare point; ZP: Zygion point; MCV: Middle cranial vault point.

Go: Gonion point; CA: Condylion anterioris; CP: Condylion posterioris; CL: Condylion lateralis; CM: Condylion medialis; CPP: Coronoid process point.

The line joining the two condylion anterioris points denotes the condylion line. The perpendicular bisector of the condylion line denotes the condylion axis. 
MSPTMAa: Angle formed by the intersection of the MSP with transverse mandibular axis (TMA). Transverse mandibular axis is defined as the line passing through the lingulae of the mandible.

RCATMAa: Angle formed by the intersection of RCA with TMA.

LCATMAa: Angle formed by the intersection of LCA with TMA.

SNAa: Angle formed between S-N plane and point A on the maxilla.

SNBa: Angle formed between S-N plane and point B on the mandible.

ANBa: Angle formed between points A, N and B.

SNPOPa: Angle formed by the occlusal plane with the S-N plane.

SNPMPa: Angle formed by the mandibular plane with the S-N plane.

The values thus derived from the clinical data, radiological data, biomechanical data and the psychological evaluation of the control group patient's gave a normal range of findings in healthy individuals with normal TMJ. The normal functioning of their TMJs was correlated with their respective findings.

\section{3) Psychological evaluation of the patient.}

When taking the case history of the patient the psychological status of the patient was evaluated using the Depression, Anxiety, Stress Scale (DASS 42) given by Lovibond. The scale, once it was completed by the patients, was evaluated and the scoring was done and the psychological status of the patients was interpreted according to the rating scale.

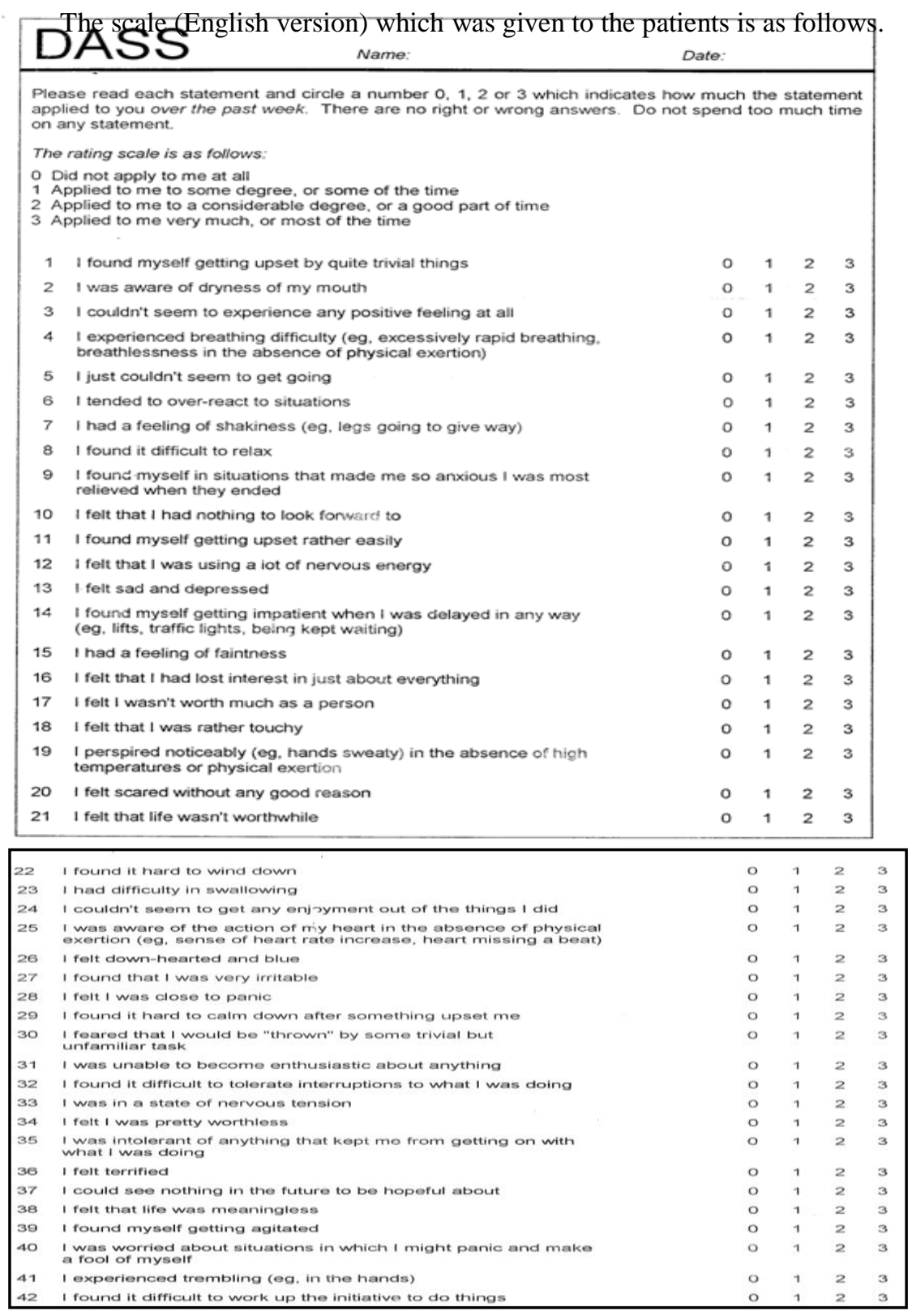


sum of the scores for each of the seven questions completed by each participant in each of the subscales are then evaluated as per the severity rating index as given below:

Severity Rating Index

$\begin{array}{lccc} & \text { DEPRESSION } & \text { ANXIETY } & \text { STRESS } \\ \text { NORMAL } & 0-9 & 0-7 & 0-14 \\ \text { MILD } & 10-13 & 8-9 & 15-18 \\ \text { MODERATE } & 14-20 & 10-14 & 19-25 \\ \text { SEVERE } & 21-27 & 15-19 & 26-33 \\ \text { EXTREMELY SEVERE } & 28+ & 20+ & 34+\end{array}$

The clinical and radiological examination of the patients included in the test group was carried out. Psychological status of the patients was also evaluated and the biomechanical evaluation was done after the three X-rays were traced. Data thus obtained from the clinical and radiological examination, biomechanical evaluation and psychological status determination of the test group patients was then entered in the observation tables for test group using the same key for analysis as used for the control group patients. A correlation was developed between the clinical presentations and the degree of derangement in the values from the control group.

\section{Observations and Results}

In this study, an attempt has been made to understand the role played by the form of the articulating surfaces of the TM joint on it's functioning by correlating the clinical, radiological and psychological data of a TM joint disorder patient and the biomechanics of the joint.

Five healthy individuals from Government Dental College and Hospital, Mumbai, who were found to have no TM joint problems on clinical and radiological examination, were selected and labelled as control group. Twenty-two patients, with signs and symptoms of TM joint disorders on clinical examination, were selected at random from the outpatient department of the same institution and were labelled as test group. A thorough clinical examination was carried out for the patients; their radiological examination included an orthopantomogram, a lateral cephalogram and a submentovertex X-ray. The biomechanical evaluation was done with the help of the linear and angular measurements done on the lateral cephalogram and submentovertex view. The psychological status of the patients was evaluated using the DASS rating scale.

Pain in the masticatory muscles was the most significant finding in majority of the patients and along with it; other clinical presentations were present such as clicking and subluxation of the TMJ, deviation of the jaw. Pain in the masticatory muscles was found in 19 test group patients $(86.36 \%)$ of which 4 patients had only pain in the masticatory muscles $(21.05 \%), 5$ patients had deviation and clicking along with pain $(26.31 \%), 4$ patients had only clicking with pain $(21.05 \%), 3$ patients had deviation along with pain (15.78\%), 2 patients had subluxation along with clicking and pain (10.52\%) and one patient had subluxation with pain $(5.26 \%)$. Remaining three patients out of 22 had only clicking of the TMJ (13.63\%).

Out of the four patients having pain in the masticatory muscles, two patients $(50 \%)$ were in the age range of 20-30 years, two patients (50\%) were in the age range of 30-40 years. Of these four patients, two were females $(50 \%)$ and two were males $(50 \%)$. Tenderness in the masticatory muscles was found to be more common on the right side $(100 \%)$. Among the muscles of mastication, the lateral pterygoid, temporalis and masseter were found most commonly affected in the study. In the radiological examination of these patients, presence of periodontal disease was a significant finding in $75 \%$ cases. Flattening of the condyles (100\%), subchondral scleroses $(50 \%)$ were among the other radiological findings in the patients having pain in the masticatory muscle apparatus. Patients having only pain in the masticatory muscles showed RCA angle in the range of 530-800 and RCATMA angle in the range of 120-370 in 75\% of cases. The SNPOP angle was also found to show variations in the range of $80-250$ in 50\% of cases. The mean scores for depression, anxiety and stress for these patients were 8.5 (mean score for control 2.2), 10.25 (mean score for control 3.8) and 19.75 (mean score for control 6.6).

Five patients, out of the 19 patients with pain in the masticatory muscles, also had clicking with deviation. Of these five patients, two patients (40\%) were in the age range of 20-30 years; two patients (40\%) were in the age range of $40-50$ years and one patient (20\%) was in the age range of 30-40 years. Of these five patients, four were females $(80 \%)$ and one was male $(20 \%)$. Deviation of the jaw to the right during excursive movements was found in $60 \%$ of the cases while to the left was found in remaining $40 \%$ cases. Pain in the lateral pterygoid, temporalis and masseter was found in $60 \%$ of cases on right side while in $40 \%$ of cases it was found on left side. In both the cases deviation of the jaw was found to be in the range of 2-3mm. Clicking of the right joint was found in $40 \%$ of cases, clicking of left joint was found in $40 \%$ cases and clicking of both the joints was found in remaining $20 \%$ cases. Missing teeth were a finding in $60 \%$ of cases. A significant finding on 
the radiological examination of these patients was the asymmetry in the outline of the skull, mandible and zygomaticomaxillary complexes $(50 \%)$ noted on the submentovertex X-ray. Patients having only pain with clicking and deviation of the jaw showed RCA angle in the range of $59^{\circ}-83^{\circ}$ and RCATMA angle in the range of $12^{0}-33^{0}$ in $60 \%$ of cases and the ICA angle in the range of $128^{0}-145^{\circ}$ in $40 \%$ of cases. The mean scores for depression, anxiety and stress for these patients were 11.5 (mean score for control 2.2), 11.75 (mean score for control 3.8) and 18.75 (mean score for control 6.6).

Three patients, out of the 19 patients having pain in the masticatory muscles, also had deviation of the jaw during excursive movements. One patient each (33.33\%) was found in the age range of 20-30 years, 30-40 years and 40-50 years respectively. Of these three patients, two were males $(66.66 \%)$ while one was female $(33.33 \%)$. In $66.66 \%$ of the cases, deviation of the jaw was seen to the right during excursive movements while in only $33.33 \%$ of the cases it was found to the left. Pain in the masticatory muscles was found to be more common in lateral pterygoid, temporalis and masseter on the right side $(66.66 \%)$ as compared to the left side $(33.33 \%)$. However, deviation of the jaw to the right was found to be only $2 \mathrm{~mm}$, while deviation to left was $5 \mathrm{~mm}$. Periodontal disease and flattening of the condyles were seen in $100 \%$ cases on radiological examination. Asymmetry in the outline of the skull was a finding in $100 \%$ of cases while asymmetry in the outline of the zygomaticomaxillary complexes was noted in $66.66 \%$ cases and asymmetry in the outline of the mandible was noted in $33.33 \%$ cases. The RCA angle was found to be in the range of $57^{\circ}-73^{\circ}$ while the RCATMA angle was in the range of $14^{0}-37^{\circ}$. The mean scores for depression, anxiety and stress for these patients were 9.33 (mean score for control 2.2), 9.66 (mean score for control 3.8) and 19 (mean score for control 6.6).

Four patients, out of the 19 patients having pain in the masticatory muscles, also had clicking of the TMJ during excursive movements. Of these four patients, two patients (50\%) were in the age range of 20-30 years, one patient was in the age range of 30-40 years (25\%) and one patient was in the age range of 60-70 years $(25 \%)$. Of these four patients, three were females $(75 \%)$ and one was a male $(25 \%) .75 \%$ of the cases had clicking of the right TMJ while $25 \%$ of the cases had bilateral clicking of the TMJ. Among the masticatory muscles, the masseter and the temporalis were more commonly affected (100\%). The radiological examination of these patients revealed periodontal disease and flattening of the condyle in $100 \%$ of cases. $75 \%$ of these patients were seen with missing teeth. The RCA angle in these patients ranged from $72^{\circ}-80^{\circ}$ and the RCATMA angle in these patients ranged from $9^{0}-17^{0}$. The mean scores for depression, anxiety and stress for these patients were 17.25 (mean score for control 2.2), 12 (mean score for control 3.8) and 21 (mean score for control 6.6).

Two patients, out of the 19 patients with pain in the masticatory muscles $(10.52 \%)$, had subluxation along with clicking of the TMJ. Both the patients were in the age range of 20-30 years (100\%) and both were females $(100 \%)$. Temporalis, masseter, sternocleidomastoid and trapezius were the muscles most commonly affected by the disease. Spacing in the dentition and missing teeth were a finding in $50 \%$ of the cases. Radiological examination revealed periodontal disease in $50 \%$ cases and flattening of the condyle in $100 \%$ cases. The RCA angle in these patients ranged from $58^{\circ}-65^{\circ}$ and the RCATMA angle in these patients ranged from $26^{\circ}-32^{\circ}$. The mean scores for depression, anxiety and stress for these patients were 6 (mean score for control 2.2), 11.5 (mean score for control 3.8) and 17.5 (mean score for control 6.6).

One patient, out of the 19 patients with pain in the masticatory muscles, had subluxation of the TMJ $(5.26 \%)$. It was a female patient in the age range of 30-40 years. This patient had tenderness of the temporalis, lateral pterygoid and sternocleidomastoid muscle. Radiological examination revealed flattening of the condyle. Missing teeth was a finding on clinical examination. The RCA angle measured $81^{\circ}$, ICA angle $153^{\circ}$, RCATMA angle measured $10^{\circ}$. The depression, anxiety and stress scores for this patient were 10,8 and 15 respectively.

Three patients, out of the 22 patients, had only clicking of the TMJ (13.63\%) during excursive movements. These patients were in the age range of 20-30 years $(100 \%)$. Of the three patients, two were males $(66.66 \%)$ and one was a female $(33.33 \%)$. Clicking was found to be more common on the left side $(66.66 \%)$ and in one case; it was bilateral $(33.33 \%)$. Radiological findings showed periodontal disease and flattening of the condyle in $100 \%$ of cases and erosion of the articulating surface in $33.33 \%$ cases. The RCA angle was in the range of $47^{\circ}-74^{0}$ for $100 \%$ cases while the LCA angle was in the range of $54^{\circ}-81^{\circ}$ and the ICA angle in the range of $101^{\circ}-156^{\circ}$ in $66.66 \%$ cases. The RCATMA angle was in the range of $16^{0}-44^{0}$ in $66.66 \%$ cases. The mean scores for depression, anxiety and stress for these patients were 8.33 (mean score for control 2.2), 12.33 (mean score for control 3.8) and 17.66 (mean score for control 6.6).

Thus, females in the 20-30 year age group were found to be more commonly affected by TMJ disorders. These disorders like pain in the masticatory muscles, clicking and subluxation of the TMJ, or deviation of the jaw most commonly affected the right side of the patient. Lateral pterygoid, temporalis and masseter were the masticatory muscles most commonly affected. Missing teeth, either on the affected side or the unaffected side was another important finding in the test group patients. Radiological findings of significance included periodontal disease and flattening of the condyles. Angles RCA and RCATMA were more commonly deranged in the test group patients from the control group. In addition, increase in the RCA angle was 
accompanied by proportionate decrease in the RCATMA angle in the test group patients. The psychological status of the test group patients was also deranged which could influence the varied clinical presentations.

DISCUSSION

The potential complexity of temporomandibular disorders can make traditional assessment and management of patients difficult. To add to this problem is the complexity of the temporomandibular joint apparatus and it's relations at the level of the base of the skull. The limitations and drawbacks of the various diagnostic aids and the seriousness of the nature of the disorders and alarming rise in cases in recent years warranted a firm approach to the management of the pathological condition and a quest to explore the new horizons in the field of diagnosis. Thus, this project was attempted to provide a better insight into the nature of the disease by developing a cost-effective diagnostic tool. The study was aimed at correlating the clinical data findings, radiological data findings, biomechanical data findings and the psychological status of the patients and explaining the various clinical presentations based on these findings.

\section{Clinical Data Findings}

The test group comprised of 22 patients, who included 14 females and 8 males selected randomly. $54.54 \%$ of the test sample population was in the age group of 21-30 years and the incidence of the TMJ disorders gradually decreased as the age of the patient increased. Of these 22 patients, $81.81 \%$ of the patients were from urban areas while the remaining from the rural areas. By nature, women might not be prone to depression, but the society makes them so. Women, in these days, have a lot of balancing to do between home and workplace, including balancing between social and personal requirements. It has the ingredients to create a lot of stress in women that can easily lead them to depression.

A working woman has to do better than men to be noticed and appreciated. In addition, if that is not tiring enough, a woman also has to look after the household work and look after their children and their studies. In addition, the misunderstandings and quarrels among the family members was one of the reasons, which was a constant worry factor for the females of the study group. Financial instability was found to be a constant worrying factor among the females of the study sample. In addition, people from the urban areas are exposed to cutthroat competition, and, with only the fittest to survive, they are compelled to leave no stone unturned to stay in the rat race. The stressful conditions to which these people are exposed tend to increase the incidence of parafunctional habits among these patients and they are found to suffer from TMJ disorders. As against this, it can be said that the people from rural areas have different priorities in life, with not very high expectations, as compared to the urban population.

$77.27 \%$ of the test group patients were found to have proclination of either the maxillary teeth or the mandibular teeth. Missing teeth was a finding in almost $50 \%$ of the test group patients and spacing in the teeth was found to be present in majority of the cases. Normally, the teeth are aligned in the arches in a smooth curve with tight contacts and the axial inclination of the teeth is such that the forces applied during mastication are directed along their long axes to be absorbed by the periodontal ligament apparatus, thus preventing excessive loading of the TMJ. However, a change in the inclination of the teeth would subject the tooth to more of obliquely directed forces, which are damaging to the periodontal ligament apparatus. In addition, when teeth are in tight contact, the forces of mastication are distributed evenly among the surrounding teeth and their periodontal ligament and no single tooth is made to bear excess load. However, when spaces are present between the adjacent teeth, this shielding effect is lost and only a few teeth are made to bear the brunt of the masticatory forces. In either condition, the periodontal support of the teeth is compromised and as a result, the TMJ is exposed to more damaging forces. Thus, proclination of either the maxillary teeth or the mandibular teeth, missing teeth and spacing in the teeth may be correlated with the pain in the masticatory muscles, deviation of the jaw and clicking or subluxation of the joint seen in the test group patients.

An impacted mandibular third molar was another finding, which was seen in almost all the study samples. It is well known that, the third molars cause pocket formation distal to the second molar. In addition, in cases where the impacted third molar is in very close contact with the second molar, there is very little alveolar bone distal to the roots of the second molar. As the molars bear the majority of the chewing forces, in cases where the periodontal status of the grinding teeth is affected, this may again lead to the excessive loading of the TMJ and cause degenerative changes in the articular elements of the joint. However, no such correlation could be developed for our test group patients.

Other findings such as canting of occlusion and crowding of teeth were insignificant findings in our study and so a correlation could not be developed between their presence and the various clinical presentations.

Alteration in the maxillofacial skeletal structure was a significant finding in our study, which was seen in almost $68.18 \%$ of the cases. Any discrepancy in the skeletal framework would be compensated by alteration in the dental set-up. This would result in disturbance in the occlusal alignment of the teeth and cause loss of the harmonious movement of the TMJ and in turn result in degenerative changes of the articular elements of the joint. The altered morphology of the articular elements would result in derangement of the biomechanics of the 
joint. This could also be one of the probable reasons for the varied clinical presentations, such as pain in the masticatory muscles, deviation of the jaw and clicking or subluxation of the joint seen in the test group patients.

Periodontal disease was a finding in $77.27 \%$ of the study sample. Periodontally poor teeth cannot withstand the masticatory forces and they tend to migrate along the direction of the bone loss. This change in the position of the teeth disturbs the occlusion, and this disturbance in occlusion is registered, through proprioceptive impulses from the periodontal ligaments, in the TMJ. The periodontium, which normally serves to absorb the stresses from the heavy masticatory forces, is no longer able to do so in the diseased conditions. This overloads the TMJ and results in degenerative changes in the articular elements. Thus, the morphology of the condyles is affected and results in altered biomechanics of the joint, which could be held responsible for the varied clinical presentations, such as pain in the masticatory muscles, deviation of the jaw and clicking or subluxation of the joint seen in the test group patients.

\section{Radiological data findings}

The radiological examination of the patients included an orthopantomogram (OPG), a lateral cephalogram and a submentovertex X-ray (SMV).

The quality of the bone was assessed on the OPG and was found to be moderate in all the study samples. However, this classification of the quality of the bone was done for study purpose. It can be understood that if the quality of bone is below normal, definitely the masticatory forces would load the TMJ more than normal, thereby leading to the degenerative changes and affecting the biomechanics of the joint.

In our study, bilateral flattening of the condyles was a significant finding on radiological examination of the test group patients. This bilateral flattening of the condyle could be due to the change in the morphology of the affected condyles, thereby altering the position of the medial and lateral poles of the mandibular condyle in relation to their original positions, when the condyles had a normal morphology. This may have resulted in a change in the orientation of the condylar axis with respect to the midsagittal plane and subsequently altered the condylar axis angle. In addition, the relationship of the condylar axis with the transverse mandibular axis would also change. The newly acquired relationship of the condylar axis with respect to the midsagittal plane, the transverse mandibular axis and the base of the skull would cause a change in the biomechanics of the affected joint and result in asynchronous movement of the two condyles. Loss in the harmonious movements of the condyles would in turn affect the masticatory muscles, influencing the jaw movements, and lead to dysfunction. This could be the reason for the pain in the masticatory muscles seen mostly on the right side in the test group patients. In addition, when the right side masticatory muscles are affected, their activity is reduced as compared to the unaffected side. This could be the reason for the deviation of the jaw being found more commonly on the right side in test group patients. In addition, the asynchronous movement of the articular disc with the condyle owing to the affected masticatory musculature and the derangement of the articular surfaces could be accountable for the clicking of the right TMJ being observed more frequently in the test group.

The other parameters assessed on the OPG such as the coronoid process, the symmetry between the two halves of the mandible, the two maxillae and the zygomaticomaxillary complexes did not show any significant relation with the clinical presentation. The possible explanation for this could be that the sample for study, selected at random from the outpatient department, did not show any gross structural variations, but were selected only based on signs and symptoms related to myofascial pain dysfunction syndrome (MPDS) or other TMJ disorders. As a result, on clinical as well as radiological assessment, no gross asymmetry was noted among the sample of population selected for study.

The position of the mandibular foramen was also located on the OPG with the help of measurements done along the $\mathrm{X}$ - and $\mathrm{Y}$-axis respectively. The centre of the foramen was considered for the measurements. However, the exact position of the foramen cannot be located on the OPG owing to the distortion of the image because of magnification $(1.25 \%)$. However, the aim was to locate the points to identify a plane passing through these two points or a plane parallel to the plane passing through these two points. The lingula is a tongue shaped projection in close proximity to the mandibular foramen, which has the attachment of the sphenomandibular ligament. With the movements of the mandible, the ligament becomes taut and will act as a fulcrum along which the mandible will rotate. Thus, these two points were used to define the transverse mandibular axis along which rotation of the mandible can be expected.

In the cephalometric analysis done on the lateral cephalogram, retrognathic mandible was a finding in $9.09 \%$ cases while retrognathic maxilla and mandible was seen in $27.27 \%$ cases. On the other hand, prognathic maxilla as well as mandible was a finding in $22.72 \%$ cases while prognathic maxilla was seen in $18.18 \%$ cases. Thus, it was seen that among the study sample, majority of the patients had both their jaws in a retruded relationship with the base of the skull; followed next in frequency by cases of bimaxillary protrusion and prognathic maxilla. The discrepancies in the skeletal framework affect the movements of the jaw. Also, because of these discrepancies, the space available for the dentition is also affected, decreasing in cases where the jaws are retrognathic and causing crowding of teeth; and being out of proportion in cases where the jaws are 
prognathic. This indirectly affects the occlusion of the patient and in turn affects the TMJ. This may be a possible explanation for the pain in the masticatory muscles, deviation of the jaw and clicking or subluxation of the joint seen in the test group patients.

The position of the maxillary and mandibular incisors was found to be within the normal range for almost $90 \%$ of the study sample. Hence, no possible correlation could be developed for the varied clinical presentations and the position of maxillary and mandibular incisor teeth.

The condylar shape was assessed on the SMV X-ray and was found to be of type A in 59.09\% of cases; of type B in $22.72 \%$ of cases and of type C in $13.63 \%$ of cases. This could possibly be explained based on biomechanics. The oblong shape of the condyle in type A may affect the biomechanical movement of the condyle considerably and thereby result in the varied clinical presentations such as the pain in the masticatory muscles, deviation of the jaw and clicking or subluxation of the joint seen in the test group patients.

The other parameters assessed on the submentovertex X-ray, such as, the symmetry in the outline of the skull, mandible, zygomaticomaxillary complexes, and the base of the skull for any pathological lesions did not provide any significant finding, which could be accountable for the clinical presentation. The possible explanation for this could be that the sample for study, selected at random from the outpatient department, did not show any gross structural variations, but were selected only based on signs and symptoms related to myofascial pain dysfunction syndrome (MPDS) or other TMJ disorders. As a result, on clinical as well as radiological assessment, no gross asymmetry was noted among the sample of population selected for study. This was in agreement with the study carried out by Eugene H.Williamson and Michael D.Simmons ${ }^{2}$ who studied the relationship between mandibular asymmetry and pain dysfunction. They advocated that there was no correlation between the amount of mandibular morphologic asymmetry and the amount of facial pain elicited from muscle palpation. They also said that one needs to be aware of asymmetry in all three planes of space in order to better correlate the two.

\section{Biomechanical data findings}

In the biomechanical analysis, the symmetry of the patients was assessed on the submentovertex X-ray. The assessment of symmetry at the level of the base of the skull was based on the study carried out by Forsberg $\mathrm{CT}$, Burstone $\mathrm{CJ}$ and Hanley $\mathrm{KJ}^{1}$ who conducted a study on the diagnosis and treatment planning of skeletal asymmetry with the submental-vertical radiograph. Symmetry was assessed at the cranial base level, maxillary level and mandibular level respectively using reference lines drawn, which served as the X- and Y-axis respectively. The midsagittal plane for reference was defined as a line, which was a perpendicular bisector of the line joining the two-foramen spinosum. This was in agreement with the study conducted by Y.Marmary, Y. Zilberman and Y. Mirsky ${ }^{3}$ on 86 adult skulls originating from India, for exploring the reliability of the midline drawn between the foramina spinosa on the cephalometric basilar view for the study of asymmetry of face and cranium, who concluded that, the foramina spinosa are believed to remain constant throughout growth and development of the skeleton and are relatively unaffected by the environmental factors. Moss and Salentijn ${ }^{4}$ also supported this view. In our study, minor asymmetry was noted at the cranial base level, maxillary level and the mandibular level as well. However, it did not appear to influence the clinical presentation largely. This was in agreement with the study of Shah S.M and Joshi M.R ${ }^{5}$ who said that minor asymmetries of the face are a common finding in normal individuals although they are rarely evident and generally pass unnoticed. Minor asymmetry results from the normal difference in the size or shape of bones forming the craniofacial complex.

The condylar axis is defined as a line connecting the lateral and medial pole of the condyle. This axis helps in determining the orientation of the condyle to the glenoid fossa at the level of the base of the skull. Any pathological process, which alters the position of the poles of the condyle, will also affect the condylar axis. Whenever the TMJ is exposed to damaging forces, owing to poor periodontal support or because of few missing teeth or is under the influence of inflammatory process following trauma or due to certain systemic conditions, the condyle undergoes degenerative changes, which affect the morphology of the condyle. With a change in the morphology of the condyle owing to the disease process, the position of the lateral and medial poles of the condyle is altered which influences the orientation of the condylar axis and in turn, affects the biomechanics of the joint. This could be a possible explanation for the varied clinical presentations seen in the test group patients such as pain in the masticatory musculature, clicking of the right TMJ and deviation of the jaw to the right during excursive movements.

The condylar axis angle were measured with reference to the midsagittal plane. This was in agreement with Taylor R.C, Ware W.H, Fowler D, and Kobayashi $\mathbf{J}^{6}$. In 1973, Mohl ND ${ }^{7}$ stated that majority of the degenerative changes in the condylar head begin in the lateral aspects of the joint and Greenberg ${ }^{8}$ and $^{2}$ Kreutziger ${ }^{9}$ were of the opinion that the degenerative changes affect the anterior aspect of the condylar head more commonly. In agreement with their views, it can be explained that in majority of our test group patients, having flattening of the anterolateral aspects of the condylar head, the position of the lateral pole of the condyle would shift posteriorly and result in the condylar axis being newly oriented to the base of the skull. In addition, 
in the newly shifted position of the lateral pole, the condylar angle would increase in a majority of our study cases. Thus, the newly oriented mandibular condyle to the base of the skull with it's altered position of the condylar axis and increased condylar angle may have resulted in affecting the biomechanics of the joint and can be considered as one of the reasons for the varied clinical presentations such as pain in the masticatory muscles, clicking of the TMJ and deviation of the jaw during excursive movements, seen affecting the right side of the test group patients more commonly. (Right condylar axis (RCA) angle for control group ranged from $62^{0}-67^{0}$ and for test group $47^{\circ}-83^{\circ}$; while left condylar axis (LCA) angle for control group ranged from $58^{\circ}-75^{\circ}$ and for test group $54^{0}-81^{0}$ ).

The intercondylar axis angle (ICA) is defined as the angle formed between the individual condylar axes of the respective condyles. Major M.Ash ${ }^{10}$ stated that the long axes of the condyles are in a lateral plane; and at first sight they seem to be out of alignment, since the long axes, if the lines were prolonged, would meet at a point anterior to the foramen magnum at an angle of approximately $135^{\circ}$. In our study, this angle, in control group patients, was found to be in the range of $120^{\circ}-140^{\circ}$, while in the test group patients, it was $101^{\circ}-156^{\circ}$. This angle, which is influenced by the individual condylar angles, would definitely be affected, if the disease process affected either, or both the condylar angles. This could be one of the reasons for the clinical presentations such as pain in the masticatory muscles, clicking of the TMJ and deviation of the jaw during excursive movements, seen mostly affecting the right side of the test group patients in our study. In addition, it can be assumed that if both the condylar axes were oriented normally, they would ideally meet at a point, anterior to the foramen magnum, on the midsagittal plane. A shift of the meeting point on either side of the midsagittal plane would indicate some abnormality in the mandibular condyle, which has caused a change in the orientation of the condylar axis. This can be seen in majority of our test group patients, wherein the meeting point of the twocondylar axes is found to be shifted to the left side of the midsagittal plane. This would have occurred because of the degenerative process affecting the right mandibular condyle more severely, thereby causing the right condylar axis to be oriented such that the right condylar angle was increased and the point of intersection of the two condylar axes was shifted to the left.

The MSPTMA angle is determined by the orientation of the midsagittal plane (MSP) and the transverse mandibular axis plane(TMA). In all our patients, the foramen spinosum were found to have a standard relationship at the base of the skull, in agreement with Moss and Salentijn ${ }^{4}$. However, the transverse mandibular axis plane (TMA), which was defined as a plane passing through the two lingulae, would definitely be influenced by the position of the two lingulae in a patient. Variations in the location of the lingulae on the two sides would result in inclination of the transverse mandibular axis; as opposed to the horizontally oriented TMA in a patient with both the lingulae located normally and at the same reference level. As the sphenomandibular ligament is attached to the lingulae, which becomes taut during mandibular movements and acts as a fulcrum, an inclined TMA, seen in $18.18 \%$ of test group patients, could be a possible explanation for clicking of the TMJ and deviation of the jaw to the right during excursive movements. (MSPTMA angle for control group ranged from $88^{0}-95^{\circ}$; and for test group $85^{0}-95^{\circ}$ ). Owing to the asynchronized movements of the two condyles, the test group patients may have experienced pain in the masticatory muscles.

The angles RCATMA and LCATMA, which are defined as the angles formed between the transverse mandibular axis plane (TMA) and the respective condylar axes (RCA or LCA), are affected by variations either in the orientation of the TMA or the individual condylar axes. From the explanation offered earlier, it can be seen that with an increase in the condylar axis angle, the angle formed between the respective condylar axis and TMA would decrease proportionately. In addition, with variations in the orientation of the TMA, the angle formed between the condylar axes and the TMA would be affected. The only difference with a change in the orientation of the TMA would be that, the angles formed by the TMA with both the condylar axes would be affected. Contrary to this, when a condylar axis is changed because of a change in the morphology of the affected condyle, the angle formed between the TMA and that condylar axis only would be affected, leaving the other angle unaffected. This could be one of the explanations offered for the various clinical presentations such as pain in the masticatory muscles, clicking of the TMJ and deviation of the jaw during excursive movements, seen affecting the right side of the test group patients (RCATMA angle for control group ranged from $23^{\circ}-28^{0}$; and for test group $9^{0}-44^{0}$ while LCATMA angle for control group ranged from $14^{0}-35^{\circ}$; and for test group $8^{0}$ $\left.35^{0}\right)$.

\section{Psychological status evaluation}

The psychological status of the patients in our study was evaluated using the Depression Anxiety Stress Scale 42 (DASS 42) given by Lovibond \& Lovibond (1995). The DASS is a 42 item self-report inventory that yields three factors: Depression; Anxiety; and Stress. This measure proposes that physical anxiety (fear symptomatology) and mental stress (nervous tension and nervous energy) factor-out as two distinct domains. This screening and outcome measure reflects the past 7 days. Of the 22 patients examined in the study, the mean scores for depression for females was 14.35 as against 11.37 for males; mean score for anxiety for females was 
13.35 as against 11.25 for males; mean score for stress for females was 22.21 as against 20.25 for males. From these readings, it can be interpreted that the females were more commonly affected by psychological disturbances as compared to males. This is in agreement with the "psycho-physiologic theory" advocated by Laskin and his associates. In their study, they found that $80 \%$ of their patients had a psychologic component as they gave history of other psychophysiologic diseases such as gastrointestinal ulcer, migraine headache or dermatitis. In addition, they also found significantly higher urinary excretion levels of 17-OH steroids and catecholamines, which have been linked to the stress phenomenon, than a comparable group of control patients.

Evaluation of the psychological status of the patient was included in the study because psychogenic theory is one of the important theories, which influences the clinical presentations in patients with TMJ disorders. A definite correlation was found between the various clinical presentations such as pain in the masticatory muscles, clicking of the TMJ and deviation of the jaw during excursive movements affecting the right side of the patient in our study. It can be stated that the threshold to bear pain is lowered in a psychologically disturbed patient. In addition, a psychologically disturbed patient finds it very difficult to adjust to the changed and challenging environments he is exposed to.

Thus, this study was carried out with a view to study the structural and architectural set-up of the cranio-maxillofacial apparatus. With the presumption that a normal individual with a healthy masticatory apparatus would exhibit well-balanced and synchronized jaw movements, the various deviations in the readings of the clinical, radiological and biomechanical parameters in the test group patients were used for explaining the various clinical presentations, such as pain in the masticatory apparatus, clicking of the TMJ or deviation of the jaw during excursive movements. The various readings obtained for the control group and test group patients along with their possible role in the various clinical presentations seen in the patients with TMJ disorders helped in developing a diagnostic module as outline in the discussion.

\section{SUMMARY AND CONCLUSION}

From the detailed discussion, the following conclusions can be hypothesized for this study:

1) The study helped in evolving a module for the submentovertex cephalometrics, which could be correlated with the lateral cephalometrics, as narrated in the discussion.

2) An understanding of the biomechanical principles of the TMJ was important to precisely define the nature of the disease. The inter-relationship of the condylar axes, the transverse mandibular axis and the midsagittal plane played an important role in influencing the biomechanics of the joint, and thereby, in deciding the status of the TM joint and it's influence on exhibiting the signs and symptoms which define MPDS and other TMJ disorders. The science of tribology (which deals with wear and tear and lubrication of the articulating elements of a joint) is also important in understanding the temporomandibular joint disorders.

3) The relationship of the maxilla and mandible to each other as well as to the base of the skull played an important role in deciding the status of the TMJ joint and how deviations from normal range influenced the various clinical signs and symptoms of MPDS and other TMJ disorders.

4) The occlusal relationships of the teeth present also played an equally important role in influencing the health of the TM joint.

5) A correlation of the clinical data, radiological data and the psychological status of an individual along with an understanding of the biomechanics of the TMJ was useful to define the pathogenesis of the TMJ disorders.

6) Thus, the improved version of diagnostic tool, which involved a correlation of the clinical data, radiological data, psychological health status of the individual and the biomechanics of the TM joint, was evolved in the course of the study.

Thus, it can be said that, temporomandibular disorders are a group of complex disorders with even more complexity in their relationship with the base of the skull. To have a clear understanding of the nature of the disorder affecting the joint, one should correlate it with the form-and-function relationship of the joint. Thus, it can be hypothesized that the morphology of the articulating elements of the TMJ influence the biomechanics of the joint, which in turn, is responsible for the varied clinical presentations in patients with TMJ disorders.

\section{Limitations And Future Scope}

This study, which involved an understanding of the form of the articulating elements of the TMJ and it's relation to the functioning of the joint had the following limitations:

1) Ideal sample for the study would have been those TMJ disorders associated with morbid deformities (acquired or congenital) which would give a variety of clinical presentations owing to their deviations from the normal findings in healthy population with normally functioning TM joints. However, the sample for our study was selected at random from the outpatient department who only had signs and symptoms of 
MPDS and other TMJ disorders such as pain in the masticatory apparatus, clicking of the TMJ and deviation of the jaw with not much of structural variations in the craniomaxillofacial skeletal apparatus. Hence, wide range of variations could not be obtained from the study.

2) The various measurements done may have a lot of personal error. However, this can be avoided in future by having two or three examiners doing the study, which would reduce the incidence of personal errors as there would be a check of one examiner over the other.

3) Standardization of the X-ray technique is very difficult aspect and no matter how much care is taken, some deviations are always likely to occur.

Inspite of these limitations, the diagnostic tool developed definitely may have better prospects in the future.

1) It is quoted in literature that following bilateral sagittal split osteotomies, the condyles undergo many degenerative changes. This diagnostic tool, devised from our study, may be of use for the Oral and Maxillofacial Surgeon; wherein a preoperative submentovertex cephalometric analysis of the patient to be operated can be done to note the orientation of the condylar axis. Next, after the surgery, another SMV can be taken to check for any change in the orientation of the condylar axis. This can help the surgeon to better predict the results of his surgery in future.

2) The submentovertex cephalometrics, that evolved during the course of the study, can be useful in interpreting the clinical presentations of the TMJ disorder patients. If software is developed after carrying out longitudinal studies over a larger sample size, it may be a very effective tool, which will yield faster diagnostic results.

3) This diagnostic tool will also have a predictive value; wherein if the condylar axes are oriented in such a fashion that the condylar axis angles in a normal young individual are deviated from the normal range fixed in the submentovertex cephalometrics, the diagnostician may be able to predict of the possible pathological changes that may be expected in the functioning of the affected condyle in future.

\section{References}

[1]. Clifton T. Forsberg: Diagnosis and treatment planning of skeletal asymmetry with the submental-vertical radiograph. Am. J. Orthod. March 1984; Vol.85; No.3; Page 224-237.

[2]. Eugene H.Williamson, Michael D.Simmons: Mandibular asymmetry and it's relation to pain dysfunction.

[3]. Marmary Y, Silberman Y, and Mirsky Y.: Use of foramina spinosa to determine skull midlines.Angle Orthod. 1979; 49; 263-268.

[4]. Moss MI, Salentijn I.: Differences between the functional matrices in anterior open bite and in deep overbite. Am. J. Orthod. 1971; $60 ; 264-280$.

[5]. Shah S.M, Joshi M.R: An assessment of asymmetry in the normal craniofacial complex.

[6]. Angle Orthod 1978; 48: 141-148

[7]. Taylor R.C, Ware W.H, Fowler D and Kobayashi J: A study of temporomandibular joint morphology and it's relationship to the dentition. Oral Surg 1972; 33: 1002.

[8]. Mohl ND: Alterations in the temporomandibular joint. Oral Surg 1973; 36: 625-631.

[9]. Greenberg MS: Osteoarthritis of the temporomandibular joint. In Rose LF, Kaye D (eds): Internal Medicine for dentistry, 1983, $p$ 107.

[10]. Kreutziger KL, Mahan PE: Temporomandibular degenerative joint disease: Part I. Anatomy, pathophysiology and clinical description. Oral Surg1975; 40: 165-182

[11]. Major M.Ash: Wheeler's Dental Anatomy, Physiology and Occlusion; (Sixth edition); The Temporomandibular Joints, Muscles, and Teeth, and their functions; p357.

BIOMECHANICAL DATA FINDINGS---TEST GROUP

\begin{tabular}{|c|c|c|c|c|c|c|c|c|c|c|c|c|c|c|c|c|c|c|c|c|c|c|c|c|c|c|c|c|c|c|c|c|c|}
\hline \multirow{5}{*}{$\begin{array}{l}\text { SR } \\
\text { NO }\end{array}$} & \multirow{5}{*}{ Patient's Nama } & \multirow{5}{*}{$\begin{array}{l}A g \\
\operatorname{Sex}\end{array}$} & \multicolumn{26}{|c|}{ Submentovertex malygis } & \multicolumn{5}{|c|}{ Lateral cephalogram analyzis } \\
\hline & & & \multicolumn{20}{|c|}{ Assessment of symanetry (leasurements in cm) } & \multirow{3}{*}{\multicolumn{6}{|c|}{ Angles masurud (in deggeas) }} & \multirow{3}{*}{\multicolumn{5}{|c|}{ Angles masurued (in degetei) }} \\
\hline & & & \multicolumn{4}{|c|}{$\begin{array}{c}\text { Cranial base fefeence } \\
\text { system }\end{array}$} & \multicolumn{6}{|c|}{ Naxillary reference system } & \multicolumn{10}{|c|}{ Nandibular refenance system } & & & & & & & & & & & \\
\hline & & & \multicolumn{2}{|c|}{$\mathrm{PCV}$} & \multicolumn{2}{|c|}{ MCP } & \multicolumn{2}{|c|}{ ID } & \multicolumn{2}{|c|}{ MCV } & \multicolumn{2}{|c|}{ Ang } & \multicolumn{2}{|c|}{ Go } & \multicolumn{2}{|c|}{$C D$} & \multicolumn{2}{|c|}{$\mathrm{CM}$} & \multicolumn{2}{|c|}{$\mathrm{CL}$} & \multicolumn{2}{|c|}{$c p p$} & & & & & & & & & & & \\
\hline & & & $\mathrm{L}$ & $\mathrm{R}$ & $\mathrm{L}$ & $\mathrm{R}$ & $\mathrm{L}$ & $\mathrm{R}$ & L & $\mathrm{R}$ & $\mathrm{L}$ & $\mathrm{R}$ & $\mathrm{L}$ & $\mathrm{R}$ & $\mathrm{L}$ & $\mathrm{R}$ & $\mathrm{L}$ & $\mathrm{R}$ & $\mathrm{L}$ & $\mathrm{R}$ & $\mathrm{L}$ & $\mathrm{R}$ & RCAa & $\mathrm{LCAB}$ & ICAa & $\begin{array}{l}\mathrm{N} \text { MSP } \\
\mathrm{NCA3}\end{array}$ & $\begin{array}{l}\mathrm{RCA} \\
\mathrm{DCA} A\end{array}$ & \begin{tabular}{|l|}
$L C A$ \\
$D C A_{3}$
\end{tabular} & $\mathrm{SNAa}$ & SNBa & ANBa & \begin{tabular}{|l|}
$S N P$ \\
$N \mathbb{P}_{3}$ \\
\end{tabular} & \begin{tabular}{|l}
$S N P$ \\
$O P_{3}$
\end{tabular} \\
\hline 1 & Patient 1 & 287 & $\begin{array}{l}6.7 \\
41\end{array}$ & $\begin{array}{l}68 \\
4.1 \\
4\end{array}$ & $\begin{array}{l}43 \\
3.6\end{array}$ & $\begin{array}{ll}3.4 \\
15\end{array}$ & \begin{tabular}{|l|}
6.7 \\
11
\end{tabular} & $\begin{array}{ll}69 \\
11 \\
\end{array}$ & $\begin{array}{ll}62 \\
11\end{array}$ & $\begin{array}{ll}62 \\
11\end{array}$ & \begin{tabular}{|l|}
17 \\
33 \\
\end{tabular} & $\frac{1.7}{3.2}$ & 50.0 & $\begin{array}{l}10 \\
02\end{array}$ & \begin{tabular}{|l|}
33 \\
0.8
\end{tabular} & \begin{tabular}{|l|}
33 \\
0.9 \\
\end{tabular} & $\begin{array}{ll}4.1 \\
0.7\end{array}$ & 0.7 & $\begin{array}{ll}25 \\
02 \\
\end{array}$ & $\begin{array}{l}60 \\
0.1\end{array}$ & \begin{tabular}{|l|}
48 \\
42
\end{tabular} & $\begin{array}{l}30 \\
40\end{array}$ & $\eta 2$ & 6 & 133 & 99 & 17 & 30 & 7 & 7 & $\therefore$ & 24 & 1 \\
\hline 2 & Patient2 & $31 \mathrm{M}$ & $\begin{array}{l}6.7 \\
40\end{array}$ & $\begin{array}{l}69 \\
40\end{array}$ & $\begin{array}{l}3.7 \\
43\end{array}$ & $\begin{array}{ll}38 \\
45\end{array}$ & $\begin{array}{ll}72 \\
11\end{array}$ & $\frac{7.0}{11}$ & 6.1 & $\begin{array}{l}60 \\
11\end{array}$ & \begin{tabular}{|l|}
53 \\
33
\end{tabular} & $\frac{52}{13}$ & $\begin{array}{l}48 \\
13\end{array}$ & $\begin{array}{ll}49 \\
10\end{array}$ & $\begin{array}{ll}4.7 \\
0.9\end{array}$ & $\begin{array}{ll}4.8 \\
0.6\end{array}$ & \begin{tabular}{|l|}
42 \\
0.6
\end{tabular} & \begin{tabular}{l|}
4.9 \\
0.4
\end{tabular} & \begin{tabular}{|l|}
60 \\
0.1 \\
\end{tabular} & \begin{tabular}{|l|}
63 \\
0.2 \\
\end{tabular} & \begin{tabular}{|l|}
11 \\
4.6 \\
\end{tabular} & \begin{tabular}{|l|}
46 \\
48 \\
\end{tabular} & 73 & 70 & 143 & $n$ & is & n & 36 & 83 & 3 & 16 & 10 \\
\hline 3 & Patient 3. & $35 \mathrm{M}$ & \begin{tabular}{|l|}
61 \\
3.3
\end{tabular} & $\begin{array}{l}5.7 \\
3.3\end{array}$ & \begin{tabular}{|l|}
3.3 \\
3.8 \\
\end{tabular} & $\begin{array}{l}3.0 \\
3.7\end{array}$ & $\begin{array}{l}6.2 \\
0.6 \\
\end{array}$ & $\begin{array}{l}63 \\
0.6 \\
0\end{array}$ & $\begin{array}{l}52 \\
0.6\end{array}$ & $\begin{array}{l}10 \\
0.6\end{array}$ & \begin{tabular}{|l|}
48 \\
3.4 \\
\end{tabular} & \begin{tabular}{|l|}
50 \\
3.6
\end{tabular} & $\begin{array}{l}21 \\
09\end{array}$ & $\begin{array}{l}48 \\
0.2\end{array}$ & \begin{tabular}{|l|}
31 \\
0.8 \\
\end{tabular} & \begin{tabular}{|l|}
10 \\
0.6
\end{tabular} & \begin{tabular}{|l|}
40 \\
0.7
\end{tabular} & \begin{tabular}{|l|}
43 \\
0.5
\end{tabular} & \begin{tabular}{|l|}
61 \\
0.1 \\
\end{tabular} & $\begin{array}{l}60 \\
0.7 \\
\end{array}$ & \begin{tabular}{|l|}
47 \\
33 \\
\end{tabular} & \begin{tabular}{|l|}
40 \\
34
\end{tabular} & 93 & 10 & 123 & $\infty$ & 37 & 20 & $\Omega 1$ & $\eta$ & 6 & n & 2 \\
\hline 4 & Patient 4 & $22 \mathrm{M}$ & $\begin{array}{l}6.3 \\
3.7 \\
\end{array}$ & $\begin{array}{l}6.2 \\
3.7\end{array}$ & \begin{tabular}{|l|}
3.2 \\
3.2 \\
\end{tabular} & $\begin{array}{l}3.8 \\
29\end{array}$ & $\begin{array}{l}6.5 \\
0.7 \\
\end{array}$ & $\begin{array}{l}62 \\
0.7\end{array}$ & $\begin{array}{l}5.1 \\
0.7\end{array}$ & $\begin{array}{l}5.9 \\
0.7\end{array}$ & \begin{tabular}{|l|}
4.6 \\
3.1 \\
\end{tabular} & $\begin{array}{l}48 \\
29 \\
\end{array}$ & $\begin{array}{l}45 \\
0.6 \\
\end{array}$ & $\begin{array}{l}4.7 \\
0.2\end{array}$ & \begin{tabular}{|l|}
49 \\
0.4 \\
\end{tabular} & \begin{tabular}{l|}
49 \\
0.4 \\
\end{tabular} & \begin{tabular}{|l|}
46 \\
0.3 \\
\end{tabular} & $\begin{array}{l}4.2 \\
0.2\end{array}$ & \begin{tabular}{|l|}
61 \\
0.5 \\
\end{tabular} & \begin{tabular}{|l|}
29 \\
0.3 \\
\end{tabular} & \begin{tabular}{|l|}
45 \\
43 \\
\end{tabular} & \begin{tabular}{|l|}
46 \\
4.1 \\
\end{tabular} & 76 & 9 & 135 & 90 & 15 & u & is & 83 & 2 & 21 & 8 \\
\hline 5 & Patient5 & $19 \mathrm{~N}$ & \begin{tabular}{|l|}
76 \\
32
\end{tabular} & $\begin{array}{l}63 \\
32\end{array}$ & \begin{tabular}{|l|}
41 \\
36 \\
\end{tabular} & $\begin{array}{l}3.5 \\
43\end{array}$ & \begin{tabular}{|l|}
69 \\
0.8 \\
\end{tabular} & $\begin{array}{l}67 \\
0.8 \\
\end{array}$ & $\begin{array}{l}6.7 \\
0.8\end{array}$ & $\begin{array}{l}2.7 \\
0.8\end{array}$ & \begin{tabular}{|l|}
33 \\
36
\end{tabular} & \begin{tabular}{|l|}
56 \\
32
\end{tabular} & \begin{tabular}{|l|}
46 \\
05
\end{tabular} & $\begin{array}{l}44 \\
0.1\end{array}$ & $\begin{array}{l}4.7 \\
0.7\end{array}$ & \begin{tabular}{|l|}
48 \\
11
\end{tabular} & \begin{tabular}{l|}
393 \\
09
\end{tabular} & \begin{tabular}{|l|}
36 \\
0.8
\end{tabular} & \begin{tabular}{|l|}
53 \\
01 \\
\end{tabular} & \begin{tabular}{|l|}
62 \\
03 \\
\end{tabular} & \begin{tabular}{|l|}
43 \\
31 \\
\end{tabular} & \begin{tabular}{|l|}
50 \\
33 \\
\end{tabular} & 73 & 69 & 141 & 8 & 14 & 2 & 8 & 8 & 3 & 2 & 6 \\
\hline 6 & Patient 6 & $35 \%$ & \begin{tabular}{|l|}
66 \\
34
\end{tabular} & $\begin{array}{l}6.1 \\
3.4\end{array}$ & \begin{tabular}{|l|}
3.8 \\
33 \\
\end{tabular} & $\frac{319}{3.4}$ & \begin{tabular}{l|}
62 \\
00 \\
\end{tabular} & $\begin{array}{l}62 \\
00\end{array}$ & $\frac{13}{0.0}$ & $\begin{array}{l}16 \\
0.0\end{array}$ & \begin{tabular}{|l|}
50 \\
32
\end{tabular} & \begin{tabular}{|l|}
48 \\
33
\end{tabular} & \begin{tabular}{l|}
42 \\
03
\end{tabular} & $\begin{array}{l}42 \\
10\end{array}$ & \begin{tabular}{|l|}
42 \\
0.6 \\
\end{tabular} & \begin{tabular}{|l|}
41 \\
0.5 \\
\end{tabular} & \begin{tabular}{|l|}
3.8 \\
0.4
\end{tabular} & \begin{tabular}{|l|}
39 \\
0.3
\end{tabular} & \begin{tabular}{|l|}
36 \\
03 \\
\end{tabular} & \begin{tabular}{l|}
1.7 \\
0.0
\end{tabular} & \begin{tabular}{|l|}
47 \\
3.2 \\
\end{tabular} & \begin{tabular}{|l|}
49 \\
28 \\
\end{tabular} & :1 & $\eta$ & 193 & 9 & 10 & 1 & . & 79 & 3 & 3 & 13 \\
\hline 7 & Patient? & $28 \mathrm{~F}$ & \begin{tabular}{|l|}
66 \\
20
\end{tabular} & $\begin{array}{l}68 \\
20\end{array}$ & \begin{tabular}{|l|}
3.6 \\
34
\end{tabular} & $\begin{array}{l}38 \\
34\end{array}$ & $\begin{array}{l}63 \\
04\end{array}$ & $\begin{array}{ll}65 \\
0.4 \\
0.4\end{array}$ & $\begin{array}{l}61 \\
04\end{array}$ & $\begin{array}{l}60 \\
04\end{array}$ & \begin{tabular}{|l|}
50 \\
34
\end{tabular} & \begin{tabular}{|l|}
21.1 \\
3.7
\end{tabular} & \begin{tabular}{l|}
46 \\
0.6
\end{tabular} & $\begin{array}{l}45 \\
0.2\end{array}$ & \begin{tabular}{|l|}
4.6 \\
06
\end{tabular} & \begin{tabular}{|l|}
43 \\
02
\end{tabular} & $\begin{array}{l}444 \\
03\end{array}$ & $\begin{array}{l}64 \\
09\end{array}$ & \begin{tabular}{|l|}
64 \\
06 \\
\end{tabular} & \begin{tabular}{l|}
64 \\
09
\end{tabular} & \begin{tabular}{|l|}
52 \\
33
\end{tabular} & \begin{tabular}{|l|}
50 \\
3.7
\end{tabular} & 69 & 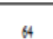 & 110 & $9 !$ & 2 & 26 & 9 & $\because$ & 4 & 30 & 20 \\
\hline 8 & Patient 8 & 287 & \begin{tabular}{|l|}
68 \\
38
\end{tabular} & $\begin{array}{l}6.1 \\
38\end{array}$ & $\begin{array}{l}41 \\
39\end{array}$ & 36 & $\begin{array}{l}65 \\
02\end{array}$ & $\begin{array}{l}60 \\
02\end{array}$ & 28 & $\begin{array}{l}5.7 \\
0.2\end{array}$ & \begin{tabular}{|l|}
49 \\
38
\end{tabular} & \begin{tabular}{|l|}
49 \\
31
\end{tabular} & $\begin{array}{l}48 \\
02\end{array}$ & $\begin{array}{l}48 \\
01\end{array}$ & $\begin{array}{l}10 \\
08\end{array}$ & \begin{tabular}{l|}
21 \\
09
\end{tabular} & \begin{tabular}{|l|}
39 \\
03
\end{tabular} & \begin{tabular}{|l|}
41 \\
03
\end{tabular} & \begin{tabular}{l|}
38 \\
01
\end{tabular} & \begin{tabular}{|l|}
39 \\
01
\end{tabular} & \begin{tabular}{|l|}
46 \\
39
\end{tabular} & \begin{tabular}{|l|}
47 \\
41 \\
\end{tabular} & 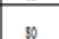 & 70 & 180 & 91 & 12 & 1 & $" s$ & 81 & 4 & 8 & 14 \\
\hline 9 & Patient9 & $23 \mathrm{M}$ & $\begin{array}{l}68 \\
36\end{array}$ & $\begin{array}{l}6.6 \\
36\end{array}$ & 3.3 & 29 & 69 & $\begin{array}{l}6.83 \\
09\end{array}$ & $\begin{array}{l}19 \\
09\end{array}$ & $\begin{array}{l}5.6 \\
09\end{array}$ & \begin{tabular}{|l|}
50 \\
33 \\
\end{tabular} & $\frac{23}{32}$ & \begin{tabular}{|l|}
53 \\
12 \\
\end{tabular} & 14 & \begin{tabular}{|l|}
53 \\
12 \\
\end{tabular} & \begin{tabular}{|l|}
54 \\
12
\end{tabular} & \begin{tabular}{l|}
40 \\
09
\end{tabular} & \begin{tabular}{|l|}
42 \\
08 \\
\end{tabular} & \begin{tabular}{|l|}
64 \\
09 \\
\end{tabular} & \begin{tabular}{l|}
6.5 \\
0.2
\end{tabular} & \begin{tabular}{|l|}
52 \\
34
\end{tabular} & \begin{tabular}{|l|}
31 \\
32
\end{tabular} & 74 & 81 & 116 & 91 & 16 & 8 & 80 & 7 & + & 24 & 10 \\
\hline 10 & Patient 10. & $45 \%$ & \begin{tabular}{|l|}
6.6 \\
3.1
\end{tabular} & $\begin{array}{l}7.4 \\
3.1\end{array}$ & \begin{tabular}{|l|}
38 \\
315
\end{tabular} & $\begin{array}{l}40 \\
315\end{array}$ & $\begin{array}{l}68 \\
13 \\
13\end{array}$ & \begin{tabular}{|c|}
69 \\
13 \\
3
\end{tabular} & $\begin{array}{l}62 \\
13\end{array}$ & \begin{tabular}{|l|}
64 \\
13
\end{tabular} & \begin{tabular}{|l|}
48 \\
34
\end{tabular} & \begin{tabular}{|l|}
49 \\
3.1
\end{tabular} & $\begin{array}{l}4.7 \\
0.3\end{array}$ & $\begin{array}{l}48 \\
\text { os }\end{array}$ & \begin{tabular}{|l|}
48 \\
0.6
\end{tabular} & \begin{tabular}{|l|}
48 \\
0.5
\end{tabular} & \begin{tabular}{|l|}
4.4 \\
0.3
\end{tabular} & \begin{tabular}{|l|}
46 \\
0.3
\end{tabular} & \begin{tabular}{|l|}
61 \\
0.7 \\
\end{tabular} & $\begin{array}{l}6 ? \\
0.5\end{array}$ & \begin{tabular}{|l|}
50 \\
45 \\
\end{tabular} & \begin{tabular}{|l|}
54 \\
41 \\
\end{tabular} & 68 & 8 & 127 & 9 & 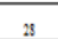 & 26 & 76 & 72 & 4 & 36 & 27 \\
\hline \begin{tabular}{|l|}
11 \\
\end{tabular} & Patient 11 & $23 \mathrm{M}$ & $\begin{array}{l}797 \\
34\end{array}$ & $\begin{array}{l}7.6 \\
34\end{array}$ & 45 & $\begin{array}{l}40 \\
44\end{array}$ & $\begin{array}{l}74 \\
0.6\end{array}$ & $\begin{array}{l}711 \\
06\end{array}$ & $\begin{array}{l}69 \\
06\end{array}$ & $\begin{array}{l}59 \\
06\end{array}$ & \begin{tabular}{|l|}
58 \\
36
\end{tabular} & $\begin{array}{l}58 \\
36\end{array}$ & \begin{tabular}{|l|}
54 \\
01 \\
\end{tabular} & $\begin{array}{l}5.6 \\
0.7\end{array}$ & $\begin{array}{l}25 \\
05\end{array}$ & \begin{tabular}{|l|}
56 \\
0.7
\end{tabular} & \begin{tabular}{|l|}
46 \\
04
\end{tabular} & \begin{tabular}{|l|}
45 \\
03
\end{tabular} & \begin{tabular}{|l|}
66 \\
07 \\
\end{tabular} & \begin{tabular}{|l|}
63 \\
03
\end{tabular} & \begin{tabular}{|l|}
49 \\
49
\end{tabular} & \begin{tabular}{|l|}
33 \\
43 \\
\end{tabular} & 57 & & & & 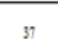 & 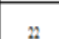 & 94 & 81 & & 2 & 6 \\
\hline 12 & Patient 12 & 407 & $\begin{array}{l}65 \\
23\end{array}$ & $\begin{array}{l}65 \\
23\end{array}$ & $\begin{array}{l}3.8 \\
3.5\end{array}$ & $\begin{array}{l}3.13 \\
3.1\end{array}$ & $\begin{array}{l}62 \\
0.3\end{array}$ & $\begin{array}{l}69 \\
0.5\end{array}$ & $\begin{array}{l}49 \\
0.3\end{array}$ & $\begin{array}{l}2.8 \\
0.3\end{array}$ & \begin{tabular}{|l|}
51 \\
3.3 \\
\end{tabular} & $\begin{array}{l}13 \\
4.0\end{array}$ & $\begin{array}{l}4.9 \\
0.7\end{array}$ & $\begin{array}{l}4.6 \\
0.4\end{array}$ & \begin{tabular}{|l|}
48 \\
10 \\
\end{tabular} & \begin{tabular}{|l|}
48 \\
10 \\
\end{tabular} & \begin{tabular}{|l|}
39 \\
0.7 \\
\end{tabular} & $\begin{array}{l}3.9 \\
0.6\end{array}$ & $\begin{array}{l}3.9 \\
0.1 \\
\end{array}$ & $\begin{array}{l}2.8 \\
0.1\end{array}$ & \begin{tabular}{|l|}
52 \\
315 \\
\end{tabular} & \begin{tabular}{|l|}
4.8 \\
3.7
\end{tabular} & $\theta$ & 70 & 139 & 91 & 2 & 19 & $n$ & $\eta$ & $s$ & 28 & 28 \\
\hline
\end{tabular}


“A Clinicoradiological And Craniofacial Biomechanical Evaluation Of Temporomandibular ....

\begin{tabular}{|c|c|c|c|c|c|c|c|c|c|c|c|c|c|c|c|c|c|c|c|c|c|c|c|c|c|c|c|c|c|c|c|c|c|}
\hline & \multicolumn{33}{|c|}{ BIOMECHANICAL DATA FINDINGS---TEST GROUP } \\
\hline \multirow{5}{*}{$\begin{array}{l}\mathrm{SR} \\
\mathrm{NR}\end{array}$} & \multirow{5}{*}{ Patient's Name } & \multirow{5}{*}{$\begin{array}{c}\text { Age } \\
\text { Ser }\end{array}$} & \multirow{2}{*}{\multicolumn{20}{|c|}{ 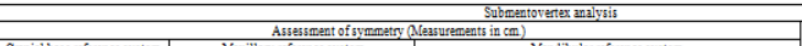 }} & \multirow{4}{*}{\multicolumn{6}{|c|}{ Angles masurued (in degreas) }} & \multirow{4}{*}{\multicolumn{5}{|c|}{$\begin{array}{l}\text { Latenl cophalogram malyyis } \\
\text { Angles measured (in degees) }\end{array}$}} \\
\hline & & & & & & & & & & & & & & & & & & & & & & & & & & & & & & & & & \\
\hline & & & \multicolumn{2}{|c|}{$\mathrm{PCV}$} & \multicolumn{2}{|c|}{ MCF } & \multicolumn{2}{|c|}{ ZP } & \multicolumn{2}{|c|}{ MCV } & \multicolumn{2}{|c|}{ Ang } & \multicolumn{2}{|c|}{$G_{0}$} & \multicolumn{2}{|c|}{$\mathrm{CP}$} & \multicolumn{2}{|c|}{$\mathrm{Cas}$} & \multicolumn{2}{|c|}{$\mathrm{CI}$} & \multirow{2}{*}{\multicolumn{2}{|c|}{$C p P$}} & & & & & & & & & & & \\
\hline & & & \multirow[b]{2}{*}{ I } & \multirow[b]{2}{*}{$\mathrm{R}$} & \multirow[b]{2}{*}{ I } & \multirow[b]{2}{*}{$\mathrm{R}$} & \multirow[b]{2}{*}{ L } & \multirow[b]{2}{*}{$\mathrm{R}$} & & & & & & & & & & & & & & & & & & & & & & & & & \\
\hline & & & & & & & & & L & $\mathrm{R}$ & $\mathrm{L}$ & $\mathrm{R}$ & L & $\mathrm{R}$ & $\mathrm{L}$ & $\mathrm{R}$ & L & $\mathrm{R}$ & L & $\mathrm{R}$ & L & $\mathrm{R}$ & RCA & LCAa & ICAa & \begin{tabular}{|l|l}
$\mathrm{NSP}$ \\
$\mathrm{N}(\mathrm{Aa}$ \\
\end{tabular} & $\begin{array}{l}\mathrm{RCA} \\
\mathrm{R} C \mathrm{~A}\end{array}$ & $\begin{array}{l}\text { LCA } \\
\text { DCAa }\end{array}$ & SNAa & $\mathrm{sNBa}$ & ANBa & $\frac{S N P}{2 N P_{1}}$ & $\begin{array}{ll}\text { SNPP } \\
\text { OPPa }\end{array}$ \\
\hline 13 & Patient 13 & $27 \%$ & $\begin{array}{ll}62 \\
3.1\end{array}$ & $\begin{array}{ll}6.1 \\
3.1\end{array}$ & \begin{tabular}{l|l|}
32 \\
3.5 \\
3
\end{tabular} & $\begin{array}{l}3.0 \\
3.4\end{array}$ & $\begin{array}{l}60 \\
0.7\end{array}$ & $\begin{array}{l}6.2 \\
0.7\end{array}$ & \begin{tabular}{l|}
5.6 \\
0.7
\end{tabular} & $\begin{array}{ll}5.4 \\
0.7\end{array}$ & \begin{tabular}{ll|}
4.7 \\
3.6
\end{tabular} & $\begin{array}{l}4.7 \\
3.6\end{array}$ & $\begin{array}{l}4.4 \\
0.7\end{array}$ & $\begin{array}{l}4.5 \\
0.8\end{array}$ & \begin{tabular}{l|}
$\begin{array}{l}43 \\
0.5\end{array}$ \\
\end{tabular} & $\begin{array}{l}45 \\
0.9 \\
\end{array}$ & $\begin{array}{ll}40 \\
0.3 \\
0.3\end{array}$ & $\begin{array}{l}4.0 \\
0.6\end{array}$ & \begin{tabular}{|l|}
58 \\
os
\end{tabular} & $\begin{array}{l}59 \\
0.2\end{array}$ & $\begin{array}{ll}4.7 \\
3.3\end{array}$ & $\begin{array}{l}4.7 \\
29\end{array}$ & $s$ & 65 & 123 & 90 & 32 & $2 s$ & 80 & 78 & 2 & 32 & 20 \\
\hline 14 & Patient 14 & $23 \mathrm{M}$ & \begin{tabular}{|l|}
64 \\
39 \\
\end{tabular} & \begin{tabular}{|l|}
66 \\
19 \\
\end{tabular} & $\begin{array}{l}3.8 \\
135 \\
\end{array}$ & $\begin{array}{l}3.4 \\
3.7 \\
\end{array}$ & \begin{tabular}{|l|}
61 \\
09 \\
\end{tabular} & 6.9 & $\begin{array}{l}23 \\
0.9 \\
\end{array}$ & $\begin{array}{l}18.8 \\
0.9 \\
\end{array}$ & $\begin{array}{l}49 \\
29\end{array}$ & $\begin{array}{l}30 \\
3.7\end{array}$ & $\begin{array}{l}4.3 \\
0.1 \\
\end{array}$ & $\begin{array}{l}42 \\
0.3 \\
\end{array}$ & $\begin{array}{l}45 \\
0.5 \\
0.5\end{array}$ & $\begin{array}{l}45 \\
0.5 \\
\end{array}$ & $\begin{array}{l}42 \\
0.2 \\
0.2\end{array}$ & $\begin{array}{l}42 \\
0.2 \\
\end{array}$ & $\begin{array}{l}62 \\
0.8 \\
\end{array}$ & $\begin{array}{l}62 \\
0.6\end{array}$ & \begin{tabular}{|l|}
4.34 \\
4.4 \\
\end{tabular} & \begin{tabular}{|l|}
47 \\
4.4 \\
\end{tabular} & 65 & 65 & 128 & ss & $n$ & 30 & 87 & 82 & $s$ & 27 & is \\
\hline 15 & Patient 15 & $25 \mathrm{~F}$ & \begin{tabular}{|l|}
68 \\
15 \\
\end{tabular} & \begin{tabular}{ll|}
64 \\
is \\
\end{tabular} & $\begin{array}{l}3.6 \\
40 \\
4\end{array}$ & $\begin{array}{l}3.6 \\
41 \\
\end{array}$ & $\begin{array}{l}61 \\
0.5 \\
\end{array}$ & $\begin{array}{l}59 \\
0.5 \\
\end{array}$ & $\begin{array}{l}\begin{array}{l}61 \\
0.5 \\
0.5\end{array} \\
\end{array}$ & $\begin{array}{l}5.6 \\
0.5 \\
\end{array}$ & $\begin{array}{ll}46 \\
3.3 \\
3\end{array}$ & $\begin{array}{l}4.7 \\
33 \\
\end{array}$ & $\begin{array}{l}43 \\
0.6 \\
\end{array}$ & $\begin{array}{l}4.3 \\
0.7 \\
\end{array}$ & \begin{tabular}{ll|}
44 \\
10 \\
\end{tabular} & $\begin{array}{l}4.4 \\
1.0 \\
\end{array}$ & \begin{tabular}{l|}
33 \\
0.7 \\
\end{tabular} & $\begin{array}{l}39 \\
0.7 \\
\end{array}$ & 0.89 & $\begin{array}{l}158 \\
0.5\end{array}$ & \begin{tabular}{|l|}
$\begin{array}{l}43 \\
3.3\end{array}$ \\
3
\end{tabular} & \begin{tabular}{|l|}
45 \\
33 \\
\end{tabular} & 8 & $s$ & 114 & 91 & 32 & 33 & 83 & 79 & 4 & 31 & 17 \\
\hline 16 & Patient 16 & $46 \mathrm{~F}$ & $\begin{array}{ll}71 \\
13\end{array}$ & $\begin{array}{ll}72 \\
13 \\
\end{array}$ & \begin{tabular}{l|}
3.7 \\
1.3 \\
\end{tabular} & $\begin{array}{l}4.4 \\
40\end{array}$ & $\begin{array}{l}71 \\
1.4 \\
\end{array}$ & $\begin{array}{l}6.58 \\
1.4\end{array}$ & $\begin{array}{l}67 \\
1.4 \\
\end{array}$ & $\begin{array}{l}6.3 \\
1.4 \\
1.4\end{array}$ & \begin{tabular}{|l|}
53 \\
135 \\
15
\end{tabular} & $\begin{array}{l}\frac{23}{13} \\
5\end{array}$ & $\begin{array}{l}49 \\
0.7 \\
\end{array}$ & $\begin{array}{l}4.8 \\
0.4 \\
\end{array}$ & $\begin{array}{ll}50 \\
11 \\
1\end{array}$ & $\begin{array}{l}50 \\
0.9 \\
\end{array}$ & $\begin{array}{l}4.1 \\
0.5 \\
0.5\end{array}$ & $\begin{array}{l}3 \\
0.5 \\
\end{array}$ & \begin{tabular}{|l|}
62 \\
60 \\
\end{tabular} & $\begin{array}{l}63 \\
0.2 \\
0.2\end{array}$ & \begin{tabular}{|l|}
50 \\
3.6 \\
\end{tabular} & \begin{tabular}{|l|}
50 \\
19 \\
\end{tabular} & 10 & 73 & 145 & $s$ & 18 & 18 & $s$ & $s$ & 3 & 2 & 14 \\
\hline 17 & Patient 17 & 63\% & & & & & & & & & & & & & & & & & & & & & & & & & & & 78 & 76 & -1 & 29 & $n$ \\
\hline 18 & Patient 18 & $47 / 8$ & $\begin{array}{l}6.6 \\
1.4 \\
\end{array}$ & $\begin{array}{l}62 \\
14 \\
\end{array}$ & $\begin{array}{ll}3.3 \\
3.7\end{array}$ & $\begin{array}{l}3.6 \\
42 \\
\end{array}$ & \begin{tabular}{|l}
63 \\
0.8 \\
\end{tabular} & $\begin{array}{l}60 \\
608\end{array}$ & 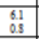 & \begin{tabular}{|l|}
5.8 \\
0.8 \\
\end{tabular} & $\begin{array}{l}49 \\
3.7 \\
\end{array}$ & $\begin{array}{l}4.7 \\
3.6\end{array}$ & $\begin{array}{l}42 \\
0.2 \\
\end{array}$ & $\begin{array}{l}43 \\
10\end{array}$ & $\begin{array}{l}4.4 \\
0.4\end{array}$ & $\begin{array}{l}43 \\
10 \\
\end{array}$ & $\begin{array}{l}42 \\
0.3 \\
0.3\end{array}$ & $\begin{array}{l}3.8 \\
0.5 \\
\end{array}$ & $\begin{array}{l}38 \\
11 \\
11\end{array}$ & $\begin{array}{l}39 \\
0.5\end{array}$ & $\begin{array}{l}40 \\
4.7 \\
4.7\end{array}$ & \begin{tabular}{|l|}
52 \\
3.7 \\
\end{tabular} & 83 & .9 & 142 & 94 & $n_{2}$ & $2 s$ & $n$ & 74 & 3 & $2 \mathrm{~s}$ & $n$ \\
\hline 19 & Patient 19 & $32 \mathrm{~F}$ & $\begin{array}{ll}6,70 \\
30\end{array}$ & 30 & $\begin{array}{l}40 \\
3.0\end{array}$ & $\frac{32}{32}$ & $\begin{array}{l}67 \\
07\end{array}$ & $\begin{array}{l}70 \\
0.7\end{array}$ & $\begin{array}{ll}62 \\
0.7\end{array}$ & \begin{tabular}{l|}
6.6 \\
0.7 \\
\end{tabular} & \begin{tabular}{ll|}
60 \\
29 \\
29
\end{tabular} & $\begin{array}{l}4.3 \\
3.3 \\
\end{array}$ & $\begin{array}{l}48 \\
05 \\
\end{array}$ & $\begin{array}{l}4.8 \\
0.4 \\
\end{array}$ & \begin{tabular}{ll|}
49 \\
10 \\
\end{tabular} & \begin{tabular}{|l|}
41 \\
10 \\
\end{tabular} & \begin{tabular}{l|}
399 \\
0.5 \\
0.5
\end{tabular} & \begin{tabular}{|l|}
43 \\
0.8 \\
\end{tabular} & \begin{tabular}{|l|}
62 \\
0.0 \\
\end{tabular} & $\begin{array}{l}60 \\
0.1 \\
0.1\end{array}$ & \begin{tabular}{|l|}
5.4 \\
3.6 \\
3
\end{tabular} & \begin{tabular}{|l|}
48 \\
3.6 \\
\end{tabular} & 9 & 31 & 140 & 92 & 33 & 8 & 74 & 73 & 1 & $n$ & 18 \\
\hline 20 & Patient 20 & $29 \mathrm{~F}$ & \begin{tabular}{ll|}
30 \\
33
\end{tabular} & $\begin{array}{ll}213 \\
33\end{array}$ & $\begin{array}{ll}37 \\
313\end{array}$ & $\begin{array}{ll}319 \\
13\end{array}$ & 31 & ${ }_{11}^{11}$ & $\begin{array}{ll}59 \\
11\end{array}$ & $\begin{array}{ll}62 \\
11 \\
\end{array}$ & $\begin{array}{ll}59 \\
35\end{array}$ & $\frac{57}{19}$ & $\begin{array}{l}45 \\
07 \\
\end{array}$ & $\begin{array}{l}47 \\
0.2\end{array}$ & $\begin{array}{l}49 \\
10\end{array}$ & \begin{tabular}{l|}
10 \\
10 \\
\end{tabular} & 6.6 & \begin{tabular}{l|l}
42 \\
0.6 \\
\end{tabular} & $\begin{array}{l}65 \\
6.0 \\
6\end{array}$ & $\begin{array}{l}65 \\
02 \\
0.2\end{array}$ & $\begin{array}{ll}5.4 \\
3.7\end{array}$ & $\frac{31}{41}$ & 50 & 76 & 158 & $s$ & 9 & 16 & $n$ & 50 & 2 & 28 & 20 \\
\hline 21 & Patieant 21 & $24 \mathrm{~F}$ & \begin{tabular}{l|l|}
74 \\
27
\end{tabular} & $\begin{array}{l}76 \\
27 \\
\end{array}$ & $\begin{array}{ll}41 \\
33\end{array}$ & $\begin{array}{l}39 \\
38\end{array}$ & \begin{tabular}{|l|l|}
69 \\
09
\end{tabular} & $\begin{array}{l}71 \\
09\end{array}$ & $\begin{array}{ll}65 \\
09\end{array}$ & $\begin{array}{ll}66 \\
09\end{array}$ & $\frac{59}{3.6}$ & $\frac{52}{19}$ & $\begin{array}{l}4.7 \\
0.5 \\
\end{array}$ & $\begin{array}{l}4.6 \\
0.4\end{array}$ & $\begin{array}{l}4.7 \\
0.7\end{array}$ & $\begin{array}{ll}4.6 \\
0.4\end{array}$ & $\begin{array}{l}4.4 \\
0.5\end{array}$ & \begin{tabular}{l|l|}
45 \\
0.2
\end{tabular} & $\begin{array}{l}6.7 \\
0.3 \\
\end{array}$ & $\begin{array}{l}69 \\
0.3\end{array}$ & $\begin{array}{l}5.44 \\
40\end{array}$ & $\begin{array}{l}30 \\
44 \\
44\end{array}$ & 50 & $n$ & $n$ & 93 & 13 & 16 & $s$ & $s s$ & 1 & 23 & 16 \\
\hline 22 & Patient 22 & $28 \mathrm{M}$ & \begin{tabular}{|l|}
$\begin{array}{l}80 \\
35 \\
\end{array}$ \\
\end{tabular} & \begin{tabular}{|l|}
32 \\
135 \\
\end{tabular} & $\begin{array}{l}45 \\
4.0 \\
40\end{array}$ & $\begin{array}{r}40 \\
44 \\
\end{array}$ & $\begin{array}{l}7.7 \\
0.0\end{array}$ & $\begin{array}{l}7.8 \\
0.0 \\
0.0\end{array}$ & $\begin{array}{l}64 \\
6.0 \\
\end{array}$ & $\begin{array}{l}69 \\
0.0 \\
0.0\end{array}$ & \begin{tabular}{l|l|}
48 \\
43 \\
4
\end{tabular} & $\begin{array}{l}5.7 \\
4.6 \\
\end{array}$ & $\begin{array}{l}55 \\
10 \\
\end{array}$ & $\begin{array}{l}5.4 \\
0.5 \\
\end{array}$ & $\begin{array}{l}.4 .4 \\
0.8 \\
\end{array}$ & \begin{tabular}{|l|l|}
5.4 \\
0.4 \\
\end{tabular} & \begin{tabular}{l|}
4.5 \\
0.7 \\
\end{tabular} & \begin{tabular}{ll|}
$\frac{21}{0.4}$ \\
\end{tabular} & $\begin{array}{l}6.6 \\
0.6 \\
\end{array}$ & $\begin{array}{l}6.8 \\
14 \\
4\end{array}$ & \begin{tabular}{|l|}
56 \\
40 \\
0
\end{tabular} & \begin{tabular}{|l|}
57 \\
4.5 \\
\end{tabular} & 47 & 54 & 101 & 91 & 4 & $3 s$ & 30 & 75 & 3 & 24 & 9 \\
\hline & Range of value & & 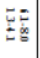 & 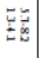 & 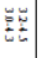 & $\dddot{\varphi}$ & 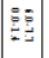 & 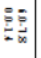 & 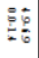 & $\frac{6}{6}$ & 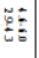 & $\overbrace{-\infty}^{0}$ & 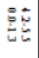 & 㩆 & 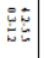 & 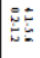 & 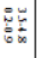 & 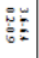 & 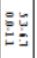 & 6 & 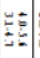 & 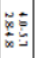 & $\stackrel{\vec{\partial}}{\ddot{x}}$ & 关 & 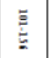 & $\frac{1}{6}$ & $\stackrel{9}{=}$ & $\stackrel{\infty}{\mathscr{E}}$ & 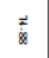 & $\ddot{*}$ & $\simeq$ & $\underline{\underline{E}}$ & $\bar{\Xi}$ \\
\hline
\end{tabular}

BIOMECHANICAL DATA FINDINGS---CONTROL GROUP

\begin{tabular}{|c|c|c|c|c|c|c|c|c|c|c|c|c|c|c|c|c|c|c|c|c|c|c|c|c|c|c|c|c|c|c|c|c|c|}
\hline \multirow{6}{*}{$\begin{array}{l}\text { SR } \\
\text { N } \\
0\end{array}$} & \multirow{6}{*}{ Pattient's Name } & \multirow{6}{*}{$\begin{array}{l}\text { Ape } \\
\text { Sex }\end{array}$} & \multirow{2}{*}{\multicolumn{20}{|c|}{ 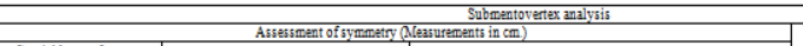 }} & \multirow{5}{*}{\multicolumn{6}{|c|}{ Angles masured (in degetei) }} & \multirow{5}{*}{\multicolumn{5}{|c|}{$\begin{array}{l}\text { Lateral cephalogram malyyis } \\
\text { Angles masured (in degeri) }\end{array}$}} \\
\hline & & & & & & & \multirow{2}{*}{\multicolumn{6}{|c|}{ Maxillary reference system }} & & & & & & & & & & & & & & & & & & & & & \\
\hline & & & \multicolumn{4}{|c|}{$\begin{array}{c}\text { Cranial base teference } \\
\text { system }\end{array}$} & & & & & & & \multicolumn{10}{|c|}{ Nandibular reference system } & & & & & & & & & & & \\
\hline & & & \multicolumn{2}{|c|}{ PCV } & \multicolumn{2}{|c|}{ MCF } & \multicolumn{2}{|c|}{$\mathbb{P}$} & \multicolumn{2}{|c|}{ MCV } & \multicolumn{2}{|c|}{ Ang } & \multicolumn{2}{|c|}{$G_{0}$} & \multicolumn{2}{|c|}{$C P$} & \multicolumn{2}{|c|}{$\mathrm{CM}$} & \multicolumn{2}{|c|}{$\mathrm{CL}$} & \multicolumn{2}{|c|}{$C P P$} & & & & & & & & & & & \\
\hline & & & & & & & & & & & & & & & & & & & & & & & & & & & & & & & & & \\
\hline & & & I & $\mathrm{R}$ & L & $\mathrm{R}$ & L & R & L & $\mathrm{R}$ & L & $\mathrm{R}$ & I & $\mathrm{R}$ & 1 & $\mathrm{R}$ & 1 & $\mathrm{R}$ & L & $\mathrm{R}$ & L & $\mathrm{R}$ & $\mathrm{RCAa}$ & ICAa & ICAa & \begin{tabular}{|c|} 
MSP \\
DCA \\
\end{tabular} & $\begin{array}{c}\mathrm{RCA} \\
\mathrm{RCA} \\
3\end{array}$ & $\begin{array}{c}\mathrm{ICA} \\
\mathrm{RCA} \\
3\end{array}$ & SNAa & SNBa & $\begin{array}{c}\mathrm{ANB} \\
\mathrm{a}\end{array}$ & \begin{tabular}{l|l}
$\operatorname{SNP}$ \\
$\mathrm{NOP}$
\end{tabular} & $\begin{array}{l}S N P \\
O P_{3}\end{array}$ \\
\hline 1 & Patient 1 & \begin{tabular}{c|}
23 \\
$F$
\end{tabular} & $\begin{array}{l}60 \\
3.4\end{array}$ & \begin{tabular}{l|}
62 \\
3.4
\end{tabular} & $\begin{array}{l}29 \\
3.0\end{array}$ & $\begin{array}{l}3.0 \\
3.0\end{array}$ & $\begin{array}{l}59 \\
1.1\end{array}$ & $\begin{array}{l}6.0 \\
1.1\end{array}$ & $\begin{array}{ll}5.2 \\
1.1\end{array}$ & $\begin{array}{l}5.3 \\
1.1\end{array}$ & $\begin{array}{l}45 \\
30\end{array}$ & $\begin{array}{l}49 \\
29\end{array}$ & $\begin{array}{l}4.4 \\
0.2\end{array}$ & $\begin{array}{l}4.4 \\
0.0\end{array}$ & $\begin{array}{l}4.6 \\
0.7\end{array}$ & $\begin{array}{l}4.6 \\
0.6\end{array}$ & $\begin{array}{l}3.8 \\
0.5\end{array}$ & $\begin{array}{l}3.8 \\
0.4\end{array}$ & $\begin{array}{l}5,7 \\
0.3\end{array}$ & $\begin{array}{l}53 \\
0.3\end{array}$ & $\begin{array}{l}43 \\
3.6\end{array}$ & $\begin{array}{l}40 \\
3.5\end{array}$ & $6 ?$ & 70 & 137 & 89 & 23 & 21 & 80 & $n$ & 3 & 29 & 15 \\
\hline 2 & Patient 2 & \begin{tabular}{|l|}
23 \\
$\mathrm{M}$
\end{tabular} & $\begin{array}{l}75 \\
1.5 \\
\end{array}$ & \begin{tabular}{|l|l|}
75 \\
15
\end{tabular} & $\begin{array}{l}444 \\
43 \\
\end{array}$ & $\begin{array}{l}3.4 \\
3.4 \\
\end{array}$ & $\begin{array}{ll}7.1 \\
0.9\end{array}$ & $\begin{array}{l}70 \\
0.9\end{array}$ & $\begin{array}{l}6.8 \\
0.9 \\
\end{array}$ & $\begin{array}{l}6.6 \\
0.9\end{array}$ & $\begin{array}{l}5.4 \\
3.5 \\
\end{array}$ & $\begin{array}{l}5.2 \\
3.4 \\
\end{array}$ & $\begin{array}{l}5.6 \\
0.5\end{array}$ & $\begin{array}{l}5.5 \\
0.1\end{array}$ & $\begin{array}{l}5.7 \\
0.8\end{array}$ & $\begin{array}{ll}5.7 \\
0.6\end{array}$ & $\begin{array}{l}4.7 \\
0.9 \\
\end{array}$ & $\begin{array}{l}4.6 \\
0.7\end{array}$ & $\begin{array}{l}6.2 \\
0.1\end{array}$ & $\begin{array}{ll}6.2 \\
0.1\end{array}$ & $\begin{array}{ll}53 \\
4.7 \\
4\end{array}$ & $\begin{array}{l}48 \\
43 \\
\end{array}$ & 62 & 58 & 120 & 88 & 26 & 35 & 83 & 81 & 2 & 22 & 9 \\
\hline 3 & Patient 3 & \begin{tabular}{|l|}
23 \\
$F$
\end{tabular} & $\begin{array}{l}6.6 \\
3.3\end{array}$ & \begin{tabular}{|l|}
6.8 \\
33
\end{tabular} & $\begin{array}{ll}3.6 \\
33 \\
\end{array}$ & $\begin{array}{l}3.6 \\
3.4 \\
\end{array}$ & $\begin{array}{l}6.5 \\
1.8\end{array}$ & $\begin{array}{l}6.6 \\
1.8\end{array}$ & $\begin{array}{ll}6.1 \\
1.8\end{array}$ & $\begin{array}{l}62 \\
1.8 \\
\end{array}$ & $\begin{array}{l}5.0 \\
3.5\end{array}$ & $\begin{array}{l}5.6 \\
29 \\
\end{array}$ & $\begin{array}{ll}4.7 \\
0.4\end{array}$ & $\begin{array}{l}4.2 \\
0.2\end{array}$ & $\begin{array}{l}4.8 \\
0.7\end{array}$ & \begin{tabular}{l|l}
48 \\
0.5
\end{tabular} & $\begin{array}{l}41 . \\
03 \\
\end{array}$ & $\begin{array}{l}4.4 \\
0.4 \\
\end{array}$ & $\begin{array}{l}6.1 \\
02 \\
\end{array}$ & $\begin{array}{ll}6.1 \\
0.5\end{array}$ & $\begin{array}{ll}5.0 \\
4.1 \\
4\end{array}$ & $\begin{array}{l}5.0 \\
42 \\
\end{array}$ & 64 & 75 & 140 & 91 & 27 & 14 & 86 & 82 & 4 & 25 & 18 \\
\hline 4 & Patient 4 & \begin{tabular}{|l|}
23 \\
$\mathrm{~N}$ \\
\end{tabular} & $\begin{array}{l}6.8 \\
41 \\
\end{array}$ & $\begin{array}{l}6.5 \\
4.1 \\
\end{array}$ & $\begin{array}{ll}3.6 \\
39 \\
9\end{array}$ & $\begin{array}{r}3.5 \\
35 \\
\end{array}$ & $\begin{array}{l}6.7 \\
1.6\end{array}$ & $\begin{array}{l}6.1 \\
1.6 \\
\end{array}$ & $\begin{array}{l}69 \\
1.6 \\
\end{array}$ & $\begin{array}{l}5.4 \\
1.6 \\
\end{array}$ & $\begin{array}{l}52 \\
28 \\
\end{array}$ & $\begin{array}{l}44 \\
29 \\
\end{array}$ & $\begin{array}{l}4.7 \\
0.0\end{array}$ & $\begin{array}{l}4.7 \\
0.0\end{array}$ & $\begin{array}{l}49 \\
0.7\end{array}$ & $\begin{array}{l}49 \\
0.5 \\
\end{array}$ & $\begin{array}{l}4.1 \\
0.4 \\
\end{array}$ & $\begin{array}{l}43 \\
0.3 \\
\end{array}$ & $\begin{array}{l}5.7 \\
0.4 \\
\end{array}$ & $\begin{array}{ll}5.9 \\
0.4\end{array}$ & \begin{tabular}{l|l}
4.7 & 3 \\
3.4 & 3
\end{tabular} & $\begin{array}{l}4.7 \\
3.6 \\
\end{array}$ & 67 & 58 & 125 & 95 & 28 & 27 & 76 & 75 & 1 & 27 & 9 \\
\hline 5 & Patient 5 & \begin{tabular}{|l|}
23 \\
$\mathrm{~F}$
\end{tabular} & $\begin{array}{l}70 \\
2.8 \\
\end{array}$ & \begin{tabular}{|l|}
699 \\
28 \\
\end{tabular} & $\begin{array}{l}3.8 \\
3.7 \\
3\end{array}$ & $\begin{array}{l}3.7 \\
3.7 \\
\end{array}$ & $\begin{array}{l}7.0 \\
1.6 \\
\end{array}$ & $\begin{array}{l}7.1 \\
1.6 \\
\end{array}$ & $\begin{array}{l}6.4 \\
1.6 \\
\end{array}$ & $\begin{array}{l}64 \\
1.6 \\
\end{array}$ & $\begin{array}{r}5,5 \\
3,3 \\
\end{array}$ & \begin{tabular}{|l|}
52 \\
35 \\
\end{tabular} & $\begin{array}{l}5.0 \\
0.8 \\
\end{array}$ & $\begin{array}{l}3.0 \\
0.4 \\
\end{array}$ & $\begin{array}{l}53 \\
4.1 \\
\end{array}$ & \begin{tabular}{|l|}
53 \\
45 \\
\end{tabular} & $\begin{array}{l}4.7 \\
022 \\
\end{array}$ & $\begin{array}{l}48 \\
0.2 \\
\end{array}$ & $\begin{array}{l}6.6 \\
0.1 \\
\end{array}$ & $\begin{array}{l}6.6 \\
0.1 \\
\end{array}$ & $\begin{array}{ll}5.3 \\
4.1 \\
4\end{array}$ & \begin{tabular}{|l}
53 \\
45 \\
\end{tabular} & 65 & 61 & 126 & 91 & 26 & 28 & 86 & 82 & 4 & 21 & 13 \\
\hline & RANGE OFVAI & & $\pm \frac{1}{20}$ & 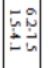 & 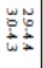 & لـ & $\begin{array}{ll}8: 6 \\
60 \\
0\end{array}$ & : & 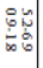 & 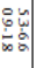 & 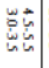 & : & 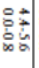 & 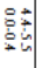 & 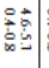 & 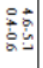 & 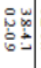 & $\underbrace{\infty}_{-\infty}$ & b. & 它望: & $=0$ & 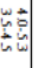 & సิ & $\stackrel{\leftrightarrow}{\leftrightarrow}$ & 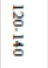 & \begin{tabular}{l}
$\infty$ \\
\multirow{6}{\infty}{} \\
$\stackrel{\omega}{\omega}$
\end{tabular} & $\underset{\infty}{\tilde{N}}$ & $\bar{z}_{\mathrm{u}}$ & 商 & 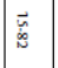 & 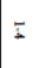 & $\stackrel{\sim}{\dot{*}}$ & $\frac{\varphi}{\infty}$ \\
\hline
\end{tabular}

RADIOLOGICAL DATA FINDINGS---TEST GROUP

\begin{tabular}{|c|c|c|c|c|c|c|c|c|c|c|c|c|c|c|c|c|c|c|c|c|c|c|c|c|}
\hline \multirow[b]{2}{*}{ SENo } & \multirow[b]{2}{*}{$\begin{array}{c}\text { Pastient's } \\
\text { name }\end{array}$} & \multirow[b]{2}{*}{\begin{tabular}{|l|} 
Age \\
Ser
\end{tabular}} & \multirow[b]{2}{*}{$\begin{array}{l}\text { Bon } \\
\text { qua }\end{array}$} & \multicolumn{8}{|c|}{ 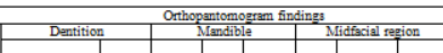 } & \multirow[b]{2}{*}{ Misc } & \multicolumn{6}{|c|}{ Lateral cephalogram findings } & \multicolumn{6}{|c|}{ Submentovertex findinges } \\
\hline & & & & Type & $\begin{array}{c}\text { Perio } \\
\text { Dis }\end{array}$ & cond & $\cos$ & symm & Max & $\underset{\mathrm{Max}}{\mathrm{Man}}$ & $\begin{array}{l}z_{y g} \\
\text { com }\end{array}$ & & $\begin{array}{l}\text { CB-Mx } \\
\text { (SNN in } \\
\text { deggreas) }\end{array}$ & $\begin{array}{l}\text { CB-Mn } \\
\text { (SNM in } \\
\text { degreast) }\end{array}$ & 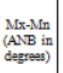 & $\underset{\substack{\text { (Readings in in } \\
\text { mim;degreat) }}}{\mathrm{NMP}}$ & $\begin{array}{c}\text { Malp } \\
\text { (Readings in } \\
\text { mmm;degreas) }\end{array}$ & Misc & Symm & Mand & $\begin{array}{c}\text { Cond } \\
\text { sh }\end{array}$ & $z_{\mathrm{yg}} \mathrm{Com}$ & Bask & Misc \\
\hline 1 & Pasteat 1 & $28 \%$ & $\mathrm{~s}$ & Petr-Ab-pos L & $2 \infty$ & $\mathrm{F}=0$ & $\mathrm{No}_{0}$ & sy & sy & 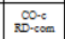 & sy & 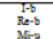 & 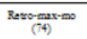 & 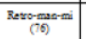 & $\begin{array}{ll}A b \\
(-2)\end{array}$ & $\begin{array}{ll}\text { Rater } \\
(9 ; 39)\end{array}$ & $\begin{array}{c}\text { Ret } \\
(4 ; 21)\end{array}$ & $\cdots-$. & \$ & sy & A & sy & No & Res-b \\
\hline 2 & Paten 2 & $31 \mathrm{M}$ & $\mathrm{s}$ & Per-Ab-po-LR & Loe & $\mathrm{F} \rightarrow \mathrm{b}$ & No & sy & Asy & 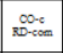 & sy & 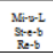 & Poogax & $\begin{array}{ll}\text { Pro-mats } \\
(\mathrm{Bg})\end{array}$ & (b) & c & $\begin{array}{l}\text { Aat } \\
(\mathrm{B} ; 313)\end{array}$ & $\cdots-$ & s & sy & s & sy & No & 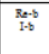 \\
\hline 3 & Pasteat & $35 \mathrm{M}$ & $\mathrm{M}$ & Pet-Ab-aspo-LR & Geas & 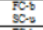 & No & sy & कy & $\begin{array}{c}0.0 .6 \\
r i s\end{array}$ & sy & - & $\begin{array}{l}\text { Ylo } \\
\text { (1i) }\end{array}$ & 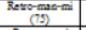 & 然 & 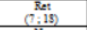 & 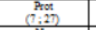 & - & sy & sy & B & sy & No & - \\
\hline 4 & $\begin{array}{ll}\text { Patsece } 4 \\
\end{array}$ & $22 \mathrm{M}$ & $\mathrm{M}$ & Petr-Ab-po- $\bar{R}$ & 200 & 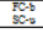 & No & Sy & $5 y$ & $\begin{array}{c}0.6-6 \\
\text { ind }\end{array}$ & sy & - & 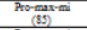 & 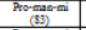 & $\begin{array}{l}10 \\
c_{2} \\
0\end{array}$ & 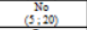 & 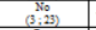 & $\ldots$ & $8 y$ & $A_{A y}=\mathrm{m}$ & $\mathrm{c}$ & sy & $N_{0}$ & - \\
\hline 5 & Pastems & $19 \mathrm{M}$ & $\mathrm{s}$ & 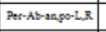 & $20 x$ & $\pi-\infty$ & $A b-\mathrm{R}$ & $A=5$ & $A y=$ & 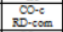 & sy & $\lim _{x \rightarrow-\infty}^{1+8}$ & 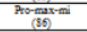 & 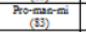 & 迹 & 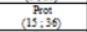 & 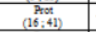 & + & $A y-m$ & Asy $m$ & 5 & $A y$ & So & Ito \\
\hline 6 & Pastem 6 & 398 & $\mathrm{M}$ & Per-Ab-po-R & Ass & Fon & No & $5 y$ & $5 y$ & 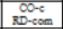 & 57 & sers & 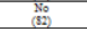 & 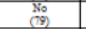 & $\begin{array}{l}\sum_{0} \\
\text { (3) }\end{array}$ & 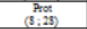 & 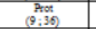 & $-\infty$ & 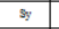 & $5 y$ & $A$ & 97 & $\mathrm{~N}_{0}$ & Re-or \\
\hline 7 & Pastent 7 & 287 & $\mathrm{M}$ & 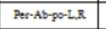 & Ass & $\mathrm{Fos}$ & No & sy & sy & 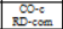 & sy & 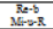 & 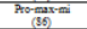 & $\begin{array}{l}\text { So } \\
\text { (5i) }\end{array}$ & At & $\frac{100}{8+30}$ & $\begin{array}{l}\text { Prom } \\
(10,4+4)\end{array}$ & $\cdots$ & sy & sy & 5 & Sy & No & Besto \\
\hline 8 & $\begin{array}{l}\text { Pasteet } \\
\end{array}$ & 285 & $\mathrm{M}$ & Per-Ab-po:LR & $20 x$ & $\mathrm{Fon}$ & No & sy & कy & 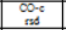 & sy & 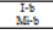 & 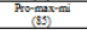 & $\begin{array}{l}\text { 就i } \\
\text { (ai) }\end{array}$ & 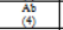 & $\begin{array}{l}\text { Set } \\
(4 ;: 10)\end{array}$ & $\begin{array}{l}\text { Ret } \\
(3 ; 1) \text { (i) }\end{array}$ & $\cdots$ & \begin{tabular}{|l|} 
Any-mi \\
\end{tabular} & sy & $A$ & sy & $N_{0}$ & Ito \\
\hline 9 & Pasteng & $23 \mathrm{M}$ & $\mathrm{M}$ & Per:Ab-po:LR & Los & 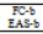 & No & $5 y$ & sy & 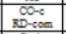 & sy & Rea-b & 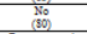 & is & $\begin{array}{l}\text { Y) } \\
\text { (2) } \\
(2)\end{array}$ & $\begin{array}{l}\text { So } \\
(\mathrm{s} ; 21)\end{array}$ & 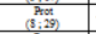 & $\ldots$ & sy & sy & B & sy & so & Resto \\
\hline 10 & Pasten 10 & $45 \%$ & $\mathrm{M}$ & \begin{tabular}{|l} 
Per-Ab-ano-L.R \\
\end{tabular} & Ges & $\pi \rightarrow b$ & No & sy & 5 & 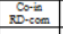 & sy & + & 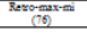 & 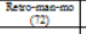 & $\begin{array}{l}4 \mathrm{~A} \\
(4) \\
(4)\end{array}$ & 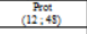 & Pato & + & $A y=\mathrm{i}$ & $5 y$ & A & sy & No & 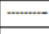 \\
\hline 11 & Patemen 11 & $23 \mathrm{M}$ & $\mathrm{M}$ & Pex:Ab-poLR & Les & $\mathrm{Fab}$ & No & sy & 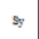 & 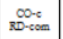 & sy & $\mathbb{R}_{\mathrm{R},-\infty}^{1, b}$ & (\$4) & (ii) & 施 & $\left(\begin{array}{l}100 \\
(4: 28)\end{array}\right.$ & $\begin{array}{c}1,10 \\
(4 ; 22)\end{array}$ & - & $A y-m$ & sy & c & $A y$ & No & Ito \\
\hline
\end{tabular}

\begin{tabular}{|c|c|c|c|c|c|c|c|c|c|c|c|c|c|c|c|c|c|c|c|c|c|c|c|c|}
\hline \multirow{3}{*}{$\mathrm{s}=\mathrm{N} \mathrm{N}_{0}$} & \multirow{3}{*}{ 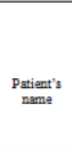 } & \multirow[b]{3}{*}{ 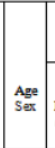 } & \multicolumn{10}{|c|}{ Orhopantomogram findings } & \multicolumn{6}{|c|}{ talogrem findings } & \multicolumn{6}{|c|}{ Submentoverter findings } \\
\hline & & & \multirow[b]{2}{*}{\begin{tabular}{c|} 
Bon. \\
and
\end{tabular}} & \multicolumn{2}{|c|}{ Dentition } & & \multicolumn{3}{|c|}{$\begin{array}{l}\text { Midfacilal region } \\
\end{array}$} & \multirow[b]{2}{*}{ Misc } & \multirow[b]{2}{*}{ 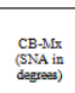 } & \multirow[b]{2}{*}{$\begin{array}{l}\text { CB-Min } \\
\text { (SNB in } \\
\text { degreses) }\end{array}$} & \multirow[b]{2}{*}{ 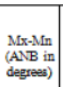 } & \multirow[b]{2}{*}{ 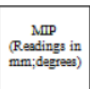 } & \multirow[b]{2}{*}{ 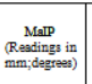 } & \multirow[b]{2}{*}{ Mikc } & \multirow[b]{2}{*}{ symm } & \multirow[b]{2}{*}{ Mend } & \multirow[b]{2}{*}{ 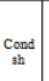 } & \multirow[b]{2}{*}{$z_{\mathrm{yg}} \mathrm{com}$} & \multirow[b]{2}{*}{ Bask } & \multirow[b]{2}{*}{ Mirc } \\
\hline & & & & Type & 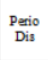 & cond & coros s & symm & Mar & $\begin{array}{c}\text { Mar } \\
\text { ain. }\end{array}$ & $\begin{array}{l}z_{y g} \\
\text { coom }\end{array}$ & & & & & & & & & & & & & \\
\hline 12 & Phiseall2 & 407 & $\mathrm{~s}$ & Perrabpoch $L$ & Asts & Fos & No & 5 & Sy & 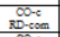 & sq & Sato & 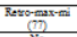 & 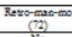 & Ab & is & Bल & - & sy & s & $\mathrm{A}$ & sf & $N_{0}$ & 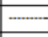 \\
\hline 13 & Pasten 13 & 218 & $\mathrm{~s}$ & 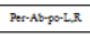 & Gete & Non & No & sy & sy & 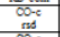 & s. & 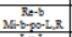 & $\frac{180}{800}$ & & & & & & $5 y$ & sy & $A$ & sy & $x_{0}$ & 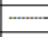 \\
\hline 14 & Patsen 14 & $23 \mathrm{M}$ & $\mathrm{s}$ & PerAbpo: L & $A s s$ & Fon & No & sy & Sy & 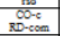 & sy & 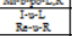 & 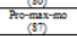 & $\frac{10}{30}$ & & 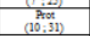 & 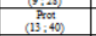 & $-\cdots$ & sy & sy & $c^{\circ}$ & sq & No & $\underline{\ldots}$ \\
\hline 15 & Pistat 15 & 258 & $\mathrm{~s}$ & Pet-Ab-apocLLR & $2 \infty x$ & 200 & No & so & Sy & 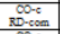 & sy & & 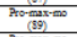 & 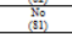 & 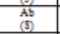 & 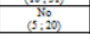 & 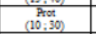 & $\cdots$ & sy & s & A & $A$ Ay & No & 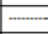 \\
\hline 16 & Photent6 & $48 \mathrm{~F}$ & $\mathrm{M}$ & 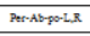 & $20 x$ & sos & No & sq & \begin{tabular}{|c|}
$5 y$ \\
\end{tabular} & 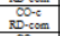 & sy & 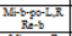 & 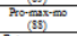 & Po (is) & & 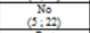 & 125 & 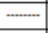 & sy & $s$ & A & sq & $\mathrm{N}_{0}$ & $\underline{-\infty}$ \\
\hline 17 & Patsent17 & 687 & $\mathrm{~s}$ & 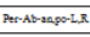 & Geses & 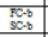 & $\mathrm{N}_{0}$ & $s$ & \begin{tabular}{|l|l|l}
$s y$ \\
\end{tabular} & 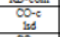 & s. & & 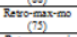 & 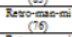 & & & & 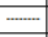 & & & & & & \\
\hline 18 & Patsen 18 & $4 \pi$ & $\mathrm{s}$ & 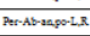 & Ges & Fos & soo & sy & sy & 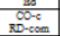 & 8 & 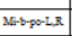 & 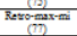 & $\operatorname{sectog} \theta=-\pi$ & 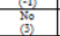 & 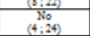 & 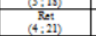 & $\cdots$ & $\mathrm{As}_{\mathrm{F}-\mathrm{mi}}^{\mathrm{m}}$ & $A^{A y-m i}$ & ${ }_{A}$ & $A y$ & $x_{0}$ & 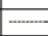 \\
\hline 19 & Patsen 19 & $32 \mathrm{P}$ & $\mathrm{M}$ & Petr-Ab-po- $\mathrm{R}$ & $20 x$ & Ro: & $N_{0}$ & sy & \begin{tabular}{|l|}
$5 y$ \\
\end{tabular} & 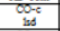 & sy & 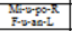 & 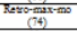 & 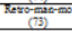 & 78 & & & $\cdots$ & $\mathrm{As}_{\mathrm{S} y \mathrm{~m}}^{\mathrm{m}}$ & $A y=-i$ & A & Asy & No & 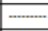 \\
\hline 20 & Pastem 20 & 297 & $\mathrm{M}$ & Pet-Ab-po-L, & Lox & 500 & soo & sf & sy & 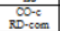 & $8 \mathrm{~s}$ & $\mathrm{Re}=\mathrm{R} \mathrm{R}$ & 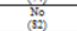 & $\frac{180}{300}$ & 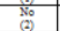 & 争 & 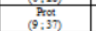 & $\cdots$ & $\$$ & $s y$ & A & sy & No & $\ldots$ \\
\hline 21 & Pastent12 & 248 & $\mathrm{M}$ & $\mathrm{B} \in \mathrm{N} \times \mathrm{N}_{\mathrm{O}}$ & Ass & Fo: & $A B$ & so & \begin{tabular}{|l|}
$s_{y}$ \\
\end{tabular} & 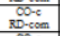 & sy & & (c) & (15) & & 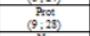 & titis & & sy & sy & $A$ & sy & no & 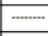 \\
\hline 22 & Pastent2 & sas & $\mathrm{s}$ & 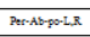 & $20 x$ & Fos & No & sy & $8 \mathrm{~s}$ & 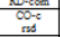 & sy & $\sum_{k=b}^{k, s}$ & 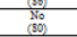 & 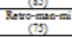 & 舟 & 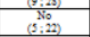 & $\frac{13}{28}$ & 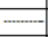 & sy & sy & $A$ & sp & $\mathrm{N}_{0}$ & 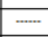 \\
\hline & anserstate & & 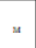 & 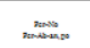 & 势 & 管: & $\approx$ & $x_{\infty}^{*}$ & 2 & 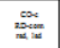 & * & 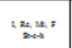 & $n$ & wat & $\therefore$ & 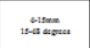 & 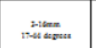 & - & $1 *$ & I. & sace & $=\infty$ & $\infty$ & :2. \\
\hline
\end{tabular}

(Patient No.17 could not complete the radiological examination owing to ill health. Hence, the blank spaces noted in the submentovertex findings.) 
“A Clinicoradiological And Craniofacial Biomechanical Evaluation Of Temporomandibular ....

\begin{tabular}{|c|c|c|c|c|c|c|c|c|c|c|c|c|c|c|c|c|c|c|c|c|c|c|c|c|}
\hline \multirow[b]{3}{*}{$\operatorname{sen} \mathrm{No}_{0}$} & \multirow[b]{3}{*}{$\begin{array}{c}\text { Patient's } \\
\text { namset }\end{array}$} & \multirow[b]{3}{*}{\begin{tabular}{|l} 
Age \\
Sex \\
\end{tabular}} & \multicolumn{16}{|c|}{ RADIOLOGICAL DATA FINDINGS - CONTROL GROUP } & \multirow{2}{*}{\multicolumn{6}{|c|}{ Subbantoverese findingst }} \\
\hline & & & \multirow[b]{2}{*}{ 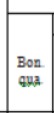 } & \multirow{2}{*}{\multicolumn{2}{|c|}{ 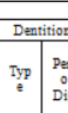 }} & \multicolumn{6}{|c|}{ 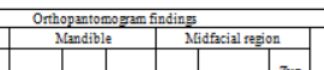 } & \multirow[b]{2}{*}{ Minc } & \multirow[b]{2}{*}{$\begin{array}{l}\text { CBNAx } \\
\text { (SNN in } \\
\text { degest) }\end{array}$} & \multirow[b]{2}{*}{ 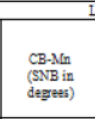 } & \multirow{2}{*}{ 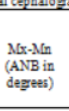 } & \multirow{2}{*}{ 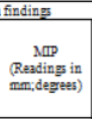 } & \multirow[b]{2}{*}{ 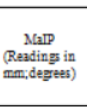 } & \multirow[b]{2}{*}{ Mas } & & & & & & \\
\hline & & & & & & cond & Coro & 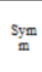 & Max & $\frac{\operatorname{Max}}{\sin }$ & $\begin{array}{l}\text { zyg } \\
\text { com }\end{array}$ & & & & & & & & 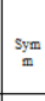 & \begin{tabular}{|c|}
$\frac{\operatorname{Man}}{\mathrm{d}}$ \\
\end{tabular} & $\begin{array}{c}c \\
c o n \\
\text { sh } \\
\text { sh }\end{array}$ & $\begin{array}{l}\text { Zyyco } \\
\text { ma }\end{array}$ & Bask & Nisic \\
\hline${ }^{1}$ & Patient 1 & $23 \mathrm{~F}$ & o & 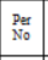 & $A b s$ & Nest & No & sy & sy & \begin{tabular}{|c|c|}
$C 0-6$ \\
$R D-60 \mathrm{~m}$
\end{tabular} & sy & I-b & $\begin{array}{l}\text { No } \\
(32)\end{array}$ & $\stackrel{\text { Retro-man-mi }}{(7)}$ & $\begin{array}{ccc}\text { No } \\
(3)\end{array}$ & $\begin{array}{c}\text { Prot } \\
(\varphi: 26)\end{array}$ & $\begin{array}{c}\text { Prot } \\
(10: 36)\end{array}$ & - & sy & sy & ${ }^{\mathrm{A}}$ & sy & No & - \\
\hline 2 & Patient 2 & \begin{tabular}{|l|}
$23 / 6$ \\
$\mathrm{M}$
\end{tabular} & $\theta$ & $\mid \begin{array}{l}\text { Pef } \\
\text { No }\end{array}$ & $A b s$ & $\mathrm{NeM}$ & No & sy & sy & $\begin{array}{c}C \mathrm{CO-c} \\
\mathrm{RD}-\mathrm{com}\end{array}$ & sy & Itb & $\underset{(83)}{\mathrm{No}}$ & $\begin{array}{l}\text { No } \\
\text { (81) }\end{array}$ & $\begin{array}{l}\text { No } \\
(2)\end{array}$ & $\begin{array}{c}\text { Prot } \\
(6 ; 24)\end{array}$ & $\begin{array}{c}N_{0} \\
(5 ; 23)\end{array}$ & - & sy & sy & A & sy & No & - \\
\hline 3 & Patient 3 & $23 \mathrm{~F}$ & $\theta$ & $\mid \begin{array}{l}\text { Pef } \\
N_{0}\end{array}$ & $A b s$ & $\mathrm{NCM}$ & No & sy & sy & $\begin{array}{c}C \mathrm{CO}-\epsilon \\
\mathrm{RD}-\mathrm{com}\end{array}$ & sy & - & $\begin{array}{c}P r 0-\max x-m i \\
(86)\end{array}$ & $\begin{array}{l}\text { No } \\
(82)\end{array}$ & $\begin{array}{l}A b \\
\text { (4) }\end{array}$ & $\left(\begin{array}{c}N_{0} \\
(5 ; 23)\end{array}\right.$ & $\begin{array}{l}\text { Prot } \\
(7: 31)\end{array}$ & - & sy & sy & A & sy & No & - \\
\hline 4 & Patient 4 & \begin{tabular}{|l|}
23 \\
$\mathrm{M}$ \\
\end{tabular} & $\theta$ & \begin{tabular}{|l|}
$\begin{array}{l}\text { Pef } \\
\text { No }\end{array}$ \\
\end{tabular} & $A B s$ & NCMS & No & sy & sy & $\begin{array}{c}c 0-c \\
\text { lidd }\end{array}$ & sy & $\mathrm{Itb}$ & $\begin{array}{c}\text { Retro-max-min } \\
(6)\end{array}$ & \begin{tabular}{|l|}
$\begin{array}{c}\text { Retro-man-mi } \\
(5)\end{array}$ \\
\end{tabular} & $\begin{array}{l}\text { No } \\
(1) \\
\end{array}$ & $\begin{array}{c}\text { Prot } \\
(12 ; 35)\end{array}$ & $\begin{array}{l}\text { Prot } \\
(; ; 35) \\
(9 ; 5)\end{array}$ & - & sy & sy & $c$ & sy & No & - \\
\hline 5 & Patient 5 & $23: \mathrm{F}$ & 0 & 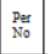 & $A b s$ & vas & No & sy & sy & 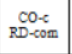 & sy & - & 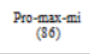 & $\begin{array}{l}\mathrm{No} \\
(32)\end{array}$ & (4) & $\begin{array}{c}\text { No } \\
(5 ; 10)\end{array}$ & Prot & - & sy & sy & A & sy & No & - \\
\hline \multicolumn{3}{|c|}{ RANGE OFVALUES } & G & $\begin{array}{l}\text { per } \\
\text { No } \\
\text { No }\end{array}$ & $A b s$ & NeMr & No & sy & sy & 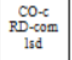 & sy & Itb & $76-86$ & $75-82$ & 14 & $5-12: 16-35$ & $5-10: 23-36$ & & sy & sy & A.C & sy & No & - \\
\hline
\end{tabular}

\begin{tabular}{|c|c|c|c|c|c|c|c|c|c|c|c|}
\hline \multirow{4}{*}{ Sr.No. } & \multicolumn{10}{|c|}{ CLINICAL DATA FINDINGS---TEST GROUP } & \multirow{4}{*}{$\begin{array}{l}\text { Any other } \\
\text { relevant } \\
\text { finding }\end{array}$} \\
\hline & \multirow{3}{*}{ Patient's name } & \multirow{3}{*}{$\begin{array}{l}\text { Age } \\
\text { Sex }\end{array}$} & \multicolumn{8}{|c|}{ Clinical parameters } & \\
\hline & & & \multirow{2}{*}{ Occlusion } & \multirow{2}{*}{$\begin{array}{c}\text { Mandibular excursive } \\
\text { movements } \\
\text { (Measurement of } \\
\text { deviation in } \mathrm{mm} \text { ) }\end{array}$} & \multicolumn{2}{|c|}{$\begin{array}{l}\text { Muscle status in } \\
\text { head- neck region }\end{array}$} & \multirow{2}{*}{$\begin{array}{c}\text { Maxillofacial } \\
\text { skeletal structure }\end{array}$} & \multicolumn{3}{|c|}{ Clinical Presentation } & \\
\hline & & & & & Extraoral & Intraoral & & Pain & Inflammation & Swelling & \\
\hline 1 & Patient 1 & $28 / \mathrm{F}$ & $\begin{array}{c}\text { OCR-I } \\
\text { Rr-Mx/Mn } \\
\mathrm{Pn}_{\mathrm{n}} \mathrm{Mxt} \\
\mathrm{I}-\mathrm{b} \\
\mathrm{FR}-\mathrm{u}-\mathrm{L}\end{array}$ & $\mathrm{CLC}-\mathrm{u}-\mathrm{R}$ & $\mathrm{NM}$ & NM & $\mathrm{Hp}-\mathrm{M}_{\mathrm{s}, \mathrm{L}_{3 \phi}}$ & 1 & 1 & $\begin{array}{c}1 \\
\left(D_{i}\right)\end{array}$ & - \\
\hline 2 & Patient 2 & $31 / \mathrm{M}$ & $\begin{array}{c}\text { OCR-I } \\
\text { Pr-Mx, } \\
\mathrm{Pn}_{\mathrm{n}-\mathrm{Mxt}, \mathrm{Mt}} \\
\mathrm{I}-\mathrm{b} \\
\mathrm{Mi}-\mathrm{u}-\mathrm{L}\end{array}$ & $\mathrm{CLC}-\mathrm{u}-\mathrm{R}$ & $D y-i$ & NM & $\mathrm{Hr}-\mathrm{M}_{3}$ & 3 & 0 & $\begin{array}{c}1 \\
(\mathrm{Di})\end{array}$ & .......... \\
\hline 3 & Patient 3 & $35 \mathrm{M}$ & $\begin{array}{c}\text { OCR-I } \\
\text { Rs - Mn } \\
\mathrm{Pn}_{n}-\mathrm{Mrt}, \mathrm{Mt}\end{array}$ & NEM & $\begin{array}{c}\text { Dy-i,j } \\
C t\end{array}$ & AOP & $\mathrm{Hp}-\mathrm{L}_{3}$ & 1 & 0 & $\begin{array}{c}1 \\
\left(D^{i}\right)\end{array}$ & 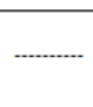 \\
\hline 4 & Patient 4 & $22 \mathrm{M}$ & $\begin{array}{l}\text { OCR-I } \\
\text { S-P(d) } \\
\text { Mi-u-L }\end{array}$ & NEM & NM & NM & NSS & 2 & 0 & $\begin{array}{c}1 \\
(\mathrm{Di})\end{array}$ & $\ldots \ldots$ \\
\hline
\end{tabular}

\begin{tabular}{|c|c|c|c|c|c|c|c|c|c|c|c|}
\hline \multirow{3}{*}{ Sr.No. } & \multirow{3}{*}{ Patient's name } & \multirow{3}{*}{$\begin{array}{l}\text { Age } \\
\text { Sex }\end{array}$} & \multicolumn{9}{|c|}{ Clinical parameters } \\
\hline & & & \multirow{2}{*}{ Occlusion } & \multirow{2}{*}{$\begin{array}{l}\text { Mandibular excursive } \\
\text { movements } \\
\text { (Measurement of } \\
\text { deviation in mm) }\end{array}$} & \multicolumn{2}{|c|}{$\begin{array}{l}\text { Muscle status in } \\
\text { head-neck region }\end{array}$} & \multirow{2}{*}{$\begin{array}{c}\text { Maxillofacial } \\
\text { skeletal structure }\end{array}$} & \multicolumn{3}{|c|}{ Clinical Presentation } & \multirow{2}{*}{$\begin{array}{l}\text { Any other } \\
\text { relevant } \\
\text { finding }\end{array}$} \\
\hline & & & & & Extraoral & Intraoral & & Pain & Inflammation & Swelling & \\
\hline 5 & Patient 5 & $18 \mathrm{M}$ & $\begin{array}{c}\text { OCR-I } \\
\text { Pr-Mx } \\
\text { Pn-Mrt, Mt } \\
\text { OCR-Cn-R } \\
\text { I-b }\end{array}$ & $\begin{array}{l}\text { DM-u-L-g } \\
\text { (5) }\end{array}$ & Dy-i,j & AOP & $\begin{array}{c}\text { Asy- }-\mathrm{M}_{2} / \mathrm{L}_{2}-\mathrm{mo} \\
\mathrm{Hp}-\mathrm{L}_{2-\infty}\end{array}$ & 1 & 0 & 0 & 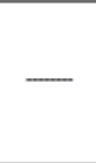 \\
\hline 6 & Patient 6 & $35 / F$ & $\begin{array}{c}\text { OCR-I } \\
\text { Pn-Mrt, Mt }\end{array}$ & $\begin{array}{l}\text { SL-without CLC and } \\
\text { p. }\end{array}$ & $\mathrm{NM}$ & $\mathrm{NM}$ & Nss & 1 & 0 & $\begin{array}{c}1 \\
\text { (Di) }\end{array}$ & - \\
\hline 7 & Patient 7 & $28 \mathrm{~F}$ & $\begin{array}{c}\text { OCR-I } \\
\text { Pr-Mx } \\
\text { Pn-Mrt, Mt } \\
\text { S-P(a,b,d) } \\
\text { FR-b }\end{array}$ & $\begin{array}{c}\text { CLC-b } \\
\text { SL with CLC with P }\end{array}$ & $\mathrm{NM}$ & $\mathrm{NM}$ & $\mathrm{Hr}-\mathrm{M}_{\mathrm{i} \rightarrow \mathrm{s}}$ & 1 & 0 & 0 & \\
\hline 8 & Patient 8 & $28 \mathrm{~F}$ & $\begin{array}{l}O C R-I \\
I-b\end{array}$ & NEM & $\mathrm{NM}$ & $\mathrm{MM}$ & NSS & 1 & 0 & 0 & - \\
\hline 9 & Patient 9 & $23 / \mathrm{M}$ & $\begin{array}{c}\text { OCR-I } \\
\mathrm{Pn}_{\mathrm{n}-\mathrm{Mxt}, \mathrm{Mt}}\end{array}$ & CLC-u-L & $\mathrm{NM}$ & $\mathrm{NM}$ & NSS & 1 & 0 & 0 & ${ }$ \\
\hline 10 & Patient 10 & $45 / \mathrm{F}$ & $\begin{array}{c}\text { OCR-I } \\
\text { Rs-Mr, Mn } \\
\text { Pn-Mrt, Mt } \\
\text { Mi-u-L; S- } \\
\text { P(c, d) }\end{array}$ & $\begin{array}{l}\text { DM-u-R-h } \\
\text { (2) }\end{array}$ & $\mathrm{NM}$ & $\mathrm{NM}$ & $\mathrm{Hp}-\mathrm{M}_{2}, \mathrm{~L}_{2-1}$ & 1 & 0 & 0 & \\
\hline
\end{tabular}


“A Clinicoradiological And Craniofacial Biomechanical Evaluation Of Temporomandibular ....

\begin{tabular}{|c|c|c|c|c|c|c|c|c|c|c|c|}
\hline \multirow{3}{*}{ Sr.No. } & \multirow{3}{*}{ Patient's name } & \multirow{3}{*}{$\begin{array}{l}\text { Age } \\
\text { Sex }\end{array}$} & \multicolumn{9}{|c|}{ Clinical perameters } \\
\hline & & & \multirow{2}{*}{ Occlusion } & \multirow{2}{*}{$\begin{array}{l}\text { Mandibular } \\
\text { excursive } \\
\text { movements } \\
\text { (Measurement of } \\
\text { deviation in mm) }\end{array}$} & \multicolumn{2}{|c|}{$\begin{array}{l}\text { Muacle status in } \\
\text { hesd-neck region }\end{array}$} & \multirow{2}{*}{$\begin{array}{c}\text { Maxillofacial } \\
\text { skeletal } \\
\text { structure }\end{array}$} & \multicolumn{3}{|c|}{ Clinical Presentation } & \multirow{2}{*}{$\begin{array}{l}\text { Any other } \\
\text { relevant finding }\end{array}$} \\
\hline & & & & & Extraoral & Intraoral & & Pain & Inflammation & Swelling & \\
\hline 11 & Patient 11 & $23 / \mathrm{M}$ & $\begin{array}{c}\text { OCR-I } \\
I-b\end{array}$ & $\begin{array}{l}\text { DM-U-R-g } \\
\text { (2) }\end{array}$ & $\mathrm{MM}$ & $\mathrm{NM}$ & NSS & 1 & 0 & 0 & - \\
\hline 12 & Patient 12 & $40 / \mathrm{F}$ & $\begin{array}{c}\text { OCR-I } \\
\mathrm{Rs}-\mathrm{Mr} / \mathrm{Mn} \\
\mathrm{Pn}-\mathrm{Mt}\end{array}$ & NEM & MM & $\mathrm{NM}$ & $\mathrm{Hp}-\mathrm{M}_{2} \mathrm{~L}_{\mathrm{s}-\mathrm{s}}$ & 2 & 0 & $\begin{array}{c}1 \\
(\mathrm{Di})\end{array}$ & \\
\hline 13 & Patient 13 & $27 / \mathrm{F}$ & $\begin{array}{c}O C R-I \\
\mathrm{Pn}_{\mathrm{n}-\mathrm{M} x t, \mathrm{Mt}}\end{array}$ & $\mathrm{CLC}-\mathrm{b}$ & $\mathrm{NM}$ & $\mathrm{NM}$ & NSS & 1 & 0 & $\begin{array}{c}1 \\
(\mathrm{Di})\end{array}$ & - \\
\hline 14 & Patient 14 & $23 / \mathrm{M}$ & $\begin{array}{c}\text { OCR-I } \\
\text { Pr-Mr, Mn } \\
\mathrm{Pr}_{-}-\mathrm{Mrt}, \mathrm{Mt} \\
\mathrm{I}-\mathrm{u}-\mathrm{L} \\
\mathrm{S}-\mathrm{P}(\mathrm{a}, \mathrm{b}, \mathrm{c}, \mathrm{d})\end{array}$ & $\begin{array}{l}\text { DM-u-L-g } \\
\text { (2) } \\
\text { CLC-u-R }\end{array}$ & $\mathrm{NM}$ & $\mathrm{NM}$ & $\mathrm{H} r-\mathrm{M}_{\mathrm{s}, \mathrm{s}}$ & 2 & 1 & 0 & \\
\hline 15 & Patient 15 & $25 / \mathrm{F}$ & $\begin{array}{c}\text { OCR-I } \\
\text { Pr-Mx; Pn-Mt } \\
\text { C-P }(c, d) ; I-b \\
\text { Mi-u-R. }\end{array}$ & SL with CLC with P & NM & $\mathrm{NM}$ & $\mathrm{Hr}-\mathrm{M}_{2, \mathrm{~s}}$ & 0 & 0 & 0 & \\
\hline 16 & Patient 16 & $46 / \mathrm{F}$ & $\begin{array}{c}\text { OCR-I } \\
\text { Pr-Mrx,Mn }\end{array}$ & $\begin{array}{l}\text { DM-u-L-g } \\
\text { (3) } \\
\text { CLC-u-L }\end{array}$ & $\mathrm{NM}$ & $\mathrm{NM}$ & $\mathrm{Hr}-\mathrm{M}_{2}, \mathrm{~L}_{2 \mathrm{~s}}$ & 1 & 0 & 0 & - \\
\hline
\end{tabular}

\begin{tabular}{|c|c|c|c|c|c|c|c|c|c|c|c|}
\hline \multirow{3}{*}{ Sr.Na. } & \multirow{3}{*}{ Patient's name } & \multirow{3}{*}{ Age/Sex } & \multicolumn{9}{|c|}{ Clinical parameters } \\
\hline & & & \multirow{2}{*}{ Occlusion } & \multirow{2}{*}{$\begin{array}{l}\text { Mandibular } \\
\text { excursive } \\
\text { movements } \\
\text { (Measurement of } \\
\text { deviation in } \mathrm{mm} \text { ) }\end{array}$} & \multicolumn{2}{|c|}{$\begin{array}{c}\text { Muscle status in bead- } \\
\text { neck region }\end{array}$} & \multirow{2}{*}{$\begin{array}{l}\text { Maxillofacial } \\
\text { skeletal structure }\end{array}$} & \multicolumn{3}{|c|}{ Clinical Presentation } & \multirow{2}{*}{$\begin{array}{l}\text { Any other } \\
\text { relevant finding }\end{array}$} \\
\hline & & & & & Extraoral & Intraoral & & Pain & Inflammation & Swelling & \\
\hline 17 & Patient 17 & $63 / F$ & $\begin{array}{c}\text { OCR-I } \\
\text { Rrs-Mr, Mn } \\
\mathrm{Pn}_{\mathrm{n}-\mathrm{Mrt}}\end{array}$ & CLC $-\mathrm{u}-\mathrm{R}$ & $D y-i, j, k, 1$ & $\mathrm{NM}$ & $\mathrm{Hp}-\mathrm{M}_{2} \mathrm{~L}_{2 s}$ & 2 & 0 & 0 & - \\
\hline 18 & Patient 18 & $47 / \mathrm{F}$ & $\begin{array}{c}\text { OCR-I } \\
\text { Rs-Mr, Mn } \\
S-P(c, d)\end{array}$ & $\begin{array}{l}\text { CLC-u-R } \\
\text { DM-u-R-g } \\
\text { (3) }\end{array}$ & Dy-i, $\mathrm{k}$ & Mig & $\mathrm{Hp}-\mathrm{M}_{\mathrm{z}, \mathrm{L}} \mathrm{L}_{2 \mathrm{~s}}$ & 2 & 0 & 0 & \\
\hline 19 & Patient 19 & $32 \mathrm{~F}$ & $\begin{array}{c}\text { OCR-I } \\
\text { Rs-Mr, Mn } \\
\mathrm{P}_{\mathrm{n}-\mathrm{M}} \mathrm{Mrt}, \mathrm{Mt}\end{array}$ & $\begin{array}{l}\text { CLC-u-L } \\
\text { DM-u-R-g } \\
\text { (2) }\end{array}$ & $\mathrm{NM}$ & $\mathrm{NM}$ & $\mathrm{Hp}-\mathrm{M}_{2}, \mathrm{~L}_{2 \phi}$ & 2 & 1 & 0 & - \\
\hline 20 & Patient 20 & $29 \mathrm{~F}$ & $\begin{array}{c}\text { OCR-I } \\
\mathrm{P}_{\mathrm{n}-\mathrm{Mxt}, \mathrm{Mt}}\end{array}$ & $c L C-b$ & $\mathrm{NM}$ & $\mathrm{NM}$ & NSS & 2 & 1 & $\begin{array}{c}1 \\
\text { (Di) }\end{array}$ & \\
\hline 21 & Patient 21 & $24 / \mathrm{F}$ & $\begin{array}{c}\text { OCR-I } \\
\text { Pr-Mx, Mn } \\
\text { Pn-Mrt,Mt }\end{array}$ & $\begin{array}{l}\mathrm{DM}-\mathrm{at}-\mathrm{R}-\mathrm{g} \\
\text { (2) } \\
\mathrm{CLC}-\mathrm{b}\end{array}$ & $\mathrm{NM}$ & $\mathrm{NM}$ & $\mathrm{Hr}=\mathrm{M}_{2} \mathrm{~L}_{2 \mathrm{~s}}$ & 1 & 0 & 0 & \\
\hline 22 & Patient 22 & $28 \mathrm{M}$ & $\begin{array}{l}\text { OCR-I, Rs-Mn } \\
\text { Pn-Mt, I-b }\end{array}$ & $\mathrm{CLC}-\mathrm{u}-\mathrm{L}$ & $\mathrm{NM}$ & $\mathrm{NM}$ & $H p-L_{i s}$ & 0 & 0 & 0 & - \\
\hline & Range of values & & $\begin{array}{c}\text { OCR-I; Rr, } \mathrm{Pr}_{\mathrm{r}} \mathrm{Pn}, \mathrm{I} \\
\mathrm{FR}, \mathrm{Mi}, \mathrm{S}, \mathrm{C} \\
\text { OCR-Cn }\end{array}$ & $\begin{array}{c}\text { CLC-u-b } \\
\text { DM-u-L,R-g,h } \\
(2-5 \mathrm{~mm}) \\
\text { SL with/without } \\
\text { CLC and P }\end{array}$ & $\begin{array}{c}\mathrm{Dy}-i, j, k, 1 \\
\mathrm{Ct}\end{array}$ & $\begin{array}{l}\text { AOP } \\
\text { Mig }\end{array}$ & $\begin{array}{c}\mathrm{Hr}, \mathrm{Hp}-\mathrm{M} 3, \mathrm{~L} 3-\mathrm{b} \\
\mathrm{Hr}-\mathrm{MB}-\mathrm{b} ; \mathrm{Hp}-\mathrm{L} 3- \\
b \\
\text { Asy-M3/L3-mo }\end{array}$ & $0-3$ & $0-3$ & 0.3 & \\
\hline
\end{tabular}


“A Clinicoradiological And Craniofacial Biomechanical Evaluation Of Temporomandibular ....

CLINICAL DATA FINDINGS---CONTROL GROUP

\begin{tabular}{|c|c|c|c|c|c|c|c|c|c|c|c|}
\hline \multirow{3}{*}{ Sr.No. } & \multirow{3}{*}{ Patient's name } & \multirow{3}{*}{ Age/Sex } & \multicolumn{9}{|c|}{ Clinical parameters } \\
\hline & & & \multirow{2}{*}{ Occlusion } & \multirow{2}{*}{$\begin{array}{l}\text { Mandibular } \\
\text { excursive } \\
\text { movements }\end{array}$} & \multicolumn{2}{|c|}{$\begin{array}{c}\text { Muscle status in head- } \\
\text { neck region }\end{array}$} & \multirow{2}{*}{$\begin{array}{c}\text { Maxillofacial } \\
\text { skeletal structure }\end{array}$} & \multicolumn{3}{|c|}{ Clinical Presentation } & \multirow{2}{*}{$\begin{array}{l}\text { Any other } \\
\text { relevant } \\
\text { finding }\end{array}$} \\
\hline & & & & & Extraoral & Intraoral & & Pain & Inflammation & Swelling & \\
\hline 1 & Control Patient 1 & $23 / F$ & $\begin{array}{c}\text { OCR-I } \\
\text { Pn-Mxt } / \mathrm{Mt} \\
\text { I-b }\end{array}$ & NEM & NM & NM & NSS & 0 & 0 & 0 & -n. \\
\hline 2 & Control Patient 2 & $23 / \mathrm{M}$ & $\begin{array}{c}\text { OCR-I } \\
\text { I-b }\end{array}$ & NEM & NM & NM & NSS & 0 & 0 & 0 & \\
\hline 3 & Control Patient 3 & $23 / F$ & $\begin{array}{l}\text { OCR-I } \\
\text { Pr-Mx } \\
\text { Pn-Mt }\end{array}$ & NEM & NM & NM & NSS & 0 & 0 & 0 & - \\
\hline 4 & Control Patient 4 & $23 / \mathrm{M}$ & $\begin{array}{c}\text { OCR-I } \\
\text { I-b }\end{array}$ & NEM & NM & NM & NSS & 0 & 0 & 0 & +....... \\
\hline 5 & Control Patient 5 & $23 / \mathrm{F}$ & $\begin{array}{l}\text { OCR-I } \\
\text { Pn-Mt }\end{array}$ & NEM & NM & NM & NSS & 0 & 0 & 0 & ........... \\
\hline & Range of values & & $\begin{array}{c}\text { OCR-I, I-b } \\
\text { Pn-Mxt } / \mathrm{Mt} \\
\mathrm{Pr}-\mathrm{Mx}\end{array}$ & NEM & NM & NM & NSS & 0 & 0 & 0 & - \\
\hline
\end{tabular}

PSYCHOLOGICAL EVALUATION TEST GROUP

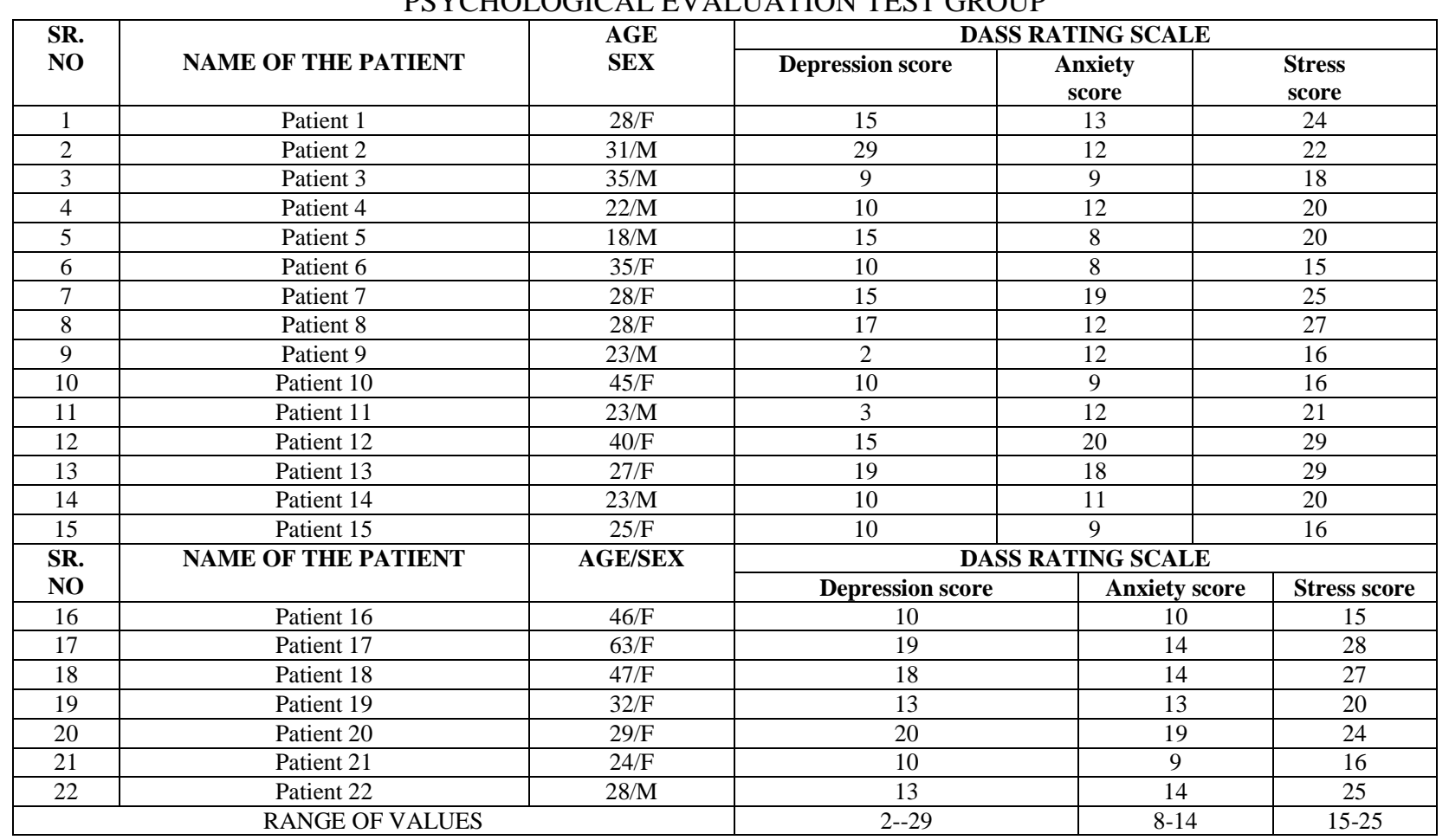

(For the master chart, kindly refer the plastic folder at the end of the bibliography).

PSYCHOLOGICAL EVALUATION CONTROL GROUP

\begin{tabular}{|c|c|c|c|c|c|}
\hline SR.NO & NAME OF THE PATIENT & \multirow{2}{*}{ AGE/SEX } & \multicolumn{2}{|c|}{ DASS RATING SCALE } \\
\cline { 4 - 6 } & & & Depression score & $\begin{array}{c}\text { Anxiety } \\
\text { score }\end{array}$ & \multicolumn{2}{c|}{$\begin{array}{c}\text { Stress } \\
\text { score }\end{array}$} \\
\hline 1 & & & 2 & 3 & 10 \\
\hline 2 & Patient 1 & $23 / \mathrm{F}$ & 1 & 4 & 5 \\
\hline 3 & Patient 2 & $23 / \mathrm{M}$ & 2 & 3 & 4 \\
\hline 4 & Patient 3 & $23 / \mathrm{F}$ & 2 & 4 & 9 \\
\hline 5 & Patient 4 & $23 / \mathrm{M}$ & 4 & $3-5$ & $4-10$ \\
\hline
\end{tabular}

